\title{
Significados que construyen niños, padres de familia y docentes vinculados a varias instituciones escolares de la ciudad de Bogotá sobre infancia, familia y escuela en el marco de la globalización*
}

\author{
Meanings built by children, family parents and teachers \\ linked to several school institutions of the city of Bogotá about \\ childhood, family and school in the frame of the globalization
}

\author{
Teresita Bernal Romero** \\ Jorge Mario Jaramillo \\ Liliana Mendoza Ramos \\ María Angélica Pérez Serna \\ Ana María Suárez Reyes
}

Universidad Santo Tomás, Bogotá

Recibido: 12 de diciembre de 2008

Revisado: 25 de febrero de 2009

Aceptado: 20 de mayo de 2009

\section{Resumen}

Esta investigación estuvo dirigida a indagar sobre los significados construidos por niños, padres de familia y profesores acerca de la infancia, la familia y la escuela en el contexto de la globalización. Se aplicó una encuesta a un grupo de 73 niños y niñas, 52 padres de familia y 52 docentes que se encontraban vinculados a varias instituciones escolares de la ciudad de Bogotá. Los resultados mostraron convergencias y divergencias entre los tres grupos de participantes, en cuanto a la forma de significar la infancia y las interacciones escolares y familiares en la actualidad. En términos generales, se observó que los niños y, en menor grado, los padres de familia tienden a una valoración positiva de los cambios asociados con la globalización, mientras que los profesores se inclinan hacia posturas más críticas. El estrato socioeconómico sirvió como variable moderadora en algunos de los significados expresados por los tres grupos de participantes en el estudio. Se discute sobre las implicacio-

Artículo producto de Investigación. Investigación institucional aprobada por la Unidad de Investigación y Postgrados de la Universidad Santo Tomás según acta publicada el 12 de diciembre de 2007 y financiada con recursos del FODEIN.

Correspondencia: Teresita Bernal. Grupo de Investigación Infantia. Facultad de Psicología, Universidad Santo Tomás. Correo electrónico: teresitabernal@ usantotomas.edu.co; telourdesbernal@yahoo.es; jorgejaramillo@usantotomas.edu.co y jaramillojorgemario@hotmail.com. Dirección postal: Autopista Norte Calle 209, Vía Arrayanes, Km. 1.5 Bogotá, Colombia. 
nes de estos resultados, haciendo especial énfasis en las demandas y retos que afronta la escuela en el marco de la globalización.

Palabras clave: significados, interacciones, infancia, familia, escuela, globalización.

\section{Abstract}

This study was managed to investigate on the meanings built by children, family parents and teachers about the childhood, the family and the school in the context of the globalization. A survey was applied at a group of 73 children and girls, 52 family parents and 52 teachers that were linked to several school institutions of the city of Bogotá. The results showed convergences and divergences among the three groups of participants concerning their current meaning about the childhood and the school and family interactions. In general, it was observed that the children and, in smaller grade, the family parents tend to a positive valuation of the changes associated with the globalization, while the teachers incline toward more critical postures. The socioeconomic stratum served as variable moderator in some of the meanings expressed by the three groups of participants in the study. In the discussion the implications of these results are analyzed, making special emphasis in the demands and challenges that the school confronts in the frame of the globalization

Key words: meanings, interactions, childhood, family, school, globalization.

\section{Introducción}

Vivimos en un mundo sometido a un ritmo acelerado de cambio, un ritmo como nunca antes lo hubo en la historia de la humanidad. Los avances en la ciencia y la tecnología han dado lugar a una verdadera revolución en el campo de la informática y las comunicaciones. En las últimas décadas no sólo han surgido nuevos medios de comunicación como Internet, los videojuegos y la telefonía celular. También los "antiguos" medios han experimentado un desarrollo vertiginoso con la introducción reciente de las nuevas tecnologías digitales.

La idea de un oyente o espectador sometido pasivamente a la acción de los medios, va siendo reemplazada poco a poco por la de personas que dialogan con y a través de los medios, hacen propuestas, votan y participan cada vez más activamente en la difusión e intercambio de informaciones (Petzold, 2001). Todo esto coincide con una expansión enorme del comercio y del sector de los servicios. Las fronteras nacionales han ido cediendo a la presión de las compañías multinacionales y, cada día más productos de muy diversos orígenes circulan con relativa libertad entre los países. Los mercados financieros han llegado a estar tan entrelazados que la crisis en alguno de ellos afecta necesariamente la estabilidad de los otros, obligándolos a introducir drásticos cambios para reacomodarse (UNICEF, 2006).

Cada vez más se consolidan los pactos políticos y económicos entre países de una misma región, así como tratados y declaraciones de derechos que tienen una cobertura mundial. Todo esto nos lleva a concluir que la regulación mutua entre los países ha aumentado notablemente, y, por tanto, también su interdependencia (UNICEF, 2006).

\section{La otra cara de la moneda: desigualdad creciente}

Además de esta regulación mutua e interdependencia, observamos también una creciente desigualdad en los niveles de desarrollo de las diferentes naciones y en el acceso que las personas de distintos lugares del mundo tienen a los bienes y beneficios que trae consigo el desarrollo industrial y la denominada sociedad de consumo (Beck, 2008). Vemos, entonces, que a pesar de contar con riqueza y tecnología suficientes para brindar un adecuado nivel de bienestar a todos 
los habitantes del mundo, lo que se constata es una expansión de la pobreza en un número muy significativo de naciones, mientras que un grupo pequeño de países y de personas que habitan en ellos monopoliza el poder y la mayoría de la riqueza existente (Dieterich, 1996, Ziegler, 2005).

La "aldea global" es, pues, por el momento, sólo una ilusión, un escenario promisorio, por todos los recursos con que cuenta y las potencialidades que encierra. Lo que prima ahora es una gran preocupación por la creciente ola de conflictos que envuelve al mundo, conflictos étnicos, religiosos y nacionales (Huntington, 1993). A lo anterior se suma el deterioro ambiental que sólo podrá ser disminuido si gentes de muy diversas culturas y procedencias nacionales logran ponerse de acuerdo sobre las prioridades del planeta y empiezan a obrar solidariamente unos con otros y con la naturaleza (Srinivas, 2007).

Éste es, en pocas palabras, el panorama que ofrece el mundo en la actualidad y que sirvió como marco general a la pregunta planteada en esta investigación: ¿Qué significados construyen los niños, padres de familia y docentes sobre la infancia, la familia y la escuela en el marco de la globalización? El interrogante tuvo su origen en el interés compartido por los investigadores de lograr una mejor comprensión sobre la forma como los seres humanos están asimilando las transformaciones y los nuevos retos que trae consigo el mundo globalizado.

\section{La situación de la infancia}

En este contexto, despiertan particular interés los significados que se están construyendo en torno a la infancia y a escenarios relacionales como la familia y la escuela, en los que los niños se educan y socializan, es decir, donde desarrollan las competencias emocionales, intelectuales y morales básicas para integrarse como sujetos portadores de derechos y de responsabilidades en la sociedad.

En relación con los niños existe un considerable debate sobre cómo interpretar los cambios que están teniendo lugar en su desarrollo. Algunos afirman que este desarrollo se ha tornado más acelerado: ciertos procesos madurativos estarían teniendo lugar más rápidamente, los niños estarían construyendo conocimiento acerca de sí mismos y su entorno físico y social más pronto que antes y, por tanto, las fases del desarrollo infantil a las que estábamos acostumbrados no tendrían ya validez en la época actual.

Se ilustra esta tendencia con la notable precocidad que muestran los niños y niñas actuales para pensar y expresarse sobre temas que antes estaban reservados a las personas adultas, el inicio cada vez más temprano de su interés por la sexualidad y la mayor autonomía que hoy demuestran frente a las decisiones o puntos de vista de los padres. Todo lo anterior estaría relacionado con una cultura sobreestimulante, en la que se está expuesto a una gran cantidad de información, al tiempo que crecen los niveles de expectativa en la sociedad adulta y particularmente en la escuela y la familia, frente a aquello que deben lograr los niños desde fases muy tempranas de su desarrollo.

Algunos psicólogos han llegado a sostener incluso que la cultura moderna está sometiendo a los niños a exigencias tan exageradas, que propicia asimismo la aparición de graves trastornos en su desarrollo (Walsh, 1993; Winterhoff, 2008). Se menciona, por ejemplo, el incremento alarmante de los trastornos de la conducta alimenticia, el consumo de alcohol u otras drogas y la violencia en las aulas escolares. Una hipótesis que está tomando un auge especial es la de un desfase entre el desarrollo cognitivo y el desarrollo socioemocional de los niños de hoy (Klippert, 2004).

Nos encontraríamos, entonces, con niños que, al tiempo que demuestran una gran capacidad de comprensión, son inmaduros emocionalmente y eso se deja entrever en una orientación inmediatista en lo que se refiere a la satisfacción de sus necesidades y deseos, baja capacidad para tolerar frustraciones y dificultades para sostener el esfuerzo ante tareas especialmente exigentes. Todo lo anterior estaría acompañado de baja autonomía y poco sentido de compromiso y responsabilidad frente a las otras personas. 
Si observamos con detenimiento este tipo de análisis sobre el perfil psicológico de los niños actuales, podemos constatar, no obstante, que es una visión necesariamente unilateral y parcial que enfoca su atención sobre un grupo de niños, probablemente aquellos que hacen parte de sectores de clase media y alta, que son más comunes en aquellos países donde se desarrolla la mayoría de la investigación psicológica. Pero, qué decir de esos otros niños que conforman la mayoría de la población infantil en los denominados países en vía de desarrollo.

Una característica particular de la globalización ha sido la de generar una mayor estratificación y desigualdad en las condiciones de vida de las personas, y esto ocurre principalmente en los países más pobres, que presentan niveles bajos o medios de desarrollo industrial y economías altamente dependientes (UNICEF, 2006, Beck, 2008). ¿Cómo viven los niños de esos países los cambios que trae consigo la globalización? ¿Qué diferencias se dan entre aquellos que pertenecen a niveles socioeconómicos medios y altos, que gozan por tanto de un buen nivel de inclusión en la sociedad, y aquellos que pertenecen a niveles socioeconómicos bajos, donde prima la exclusión de los beneficios y oportunidades de desarrollo? ¿Qué tan "global" es la influencia de la globalización? Y si lo es, o no lo es, ¿hacia dónde apunta? Todas estas preguntas merecen ser objeto de investigación, ya que aportarán elementos de orientación importantes a los educadores y a todas aquellas personas y organizaciones que tienen a su cargo promover un mejoramiento de las condiciones de vida de los niños, así como de cumplimiento de sus derechos.

\section{La situación de la familia}

También la familia, como escenario educativo de primer orden, se ha visto afectada en su estructura y funcionamiento por los cambios asociados al proceso de globalización. Ya desde las primeras décadas del siglo XX, como consecuencia indirecta de la revolución industrial, se venían dando en ella una serie de transformaciones importantes que afectaban el rol de los padres y la relación de éstos con sus hijos.
Uno de esos cambios fue el debilitamiento progresivo de la familia extensa y su sustitución gradual por la familia nuclear. Las relaciones entre padres e hijos se volvieron más estrechas e íntimas, pero aumentó la incertidumbre económica y se relajaron los lazos entre parientes de la misma generación o de distintas generaciones, que constituían una red de apoyo y representaban unos valores sobre los que el grupo familiar construía su identidad (Rice, 1997).

Un segundo cambio de gran trascendencia fue la vinculación creciente de la mujer al medio laboral y la reivindicación de sus derechos en distintos escenarios de la vida social. En la familia esto significó una redistribución gradual de los roles de hombre y mujer, a lo que se sumó el control de la natalidad y una disminución consecuente del número de hijos que tenían las familias (Florenzano, 1998).

Un tercer cambio importante fue el incremento de las rupturas conyugales con la consecuente separación o divorcio de los padres y la desintegración parcial del grupo familiar (Hayes, 2008). A partir de ahí, han surgido nuevos tipos de familia que, al lado de la familia nuclear tradicional, vienen afianzándose en los tiempos de la globalización. Está por ejemplo la familia uniparental, en la que sólo uno de los padres, usualmente la madre, queda como cabeza de la familia. Los hijos se relacionan en distintos espacios con cada uno de sus padres o pierden poco a poco la relación con alguno de ellos (Arriagada \& Aranda, 2004).

Otro tipo de familia que ha surgido es la familia compuesta, en la que los niños conviven con la nueva pareja de su madre o su padre, pudiendo ésta asumir o no el rol del padre o la madre ausente. También se están popularizando familias conformadas por personas homosexuales, con o sin hijos, familias de padres adoptantes, unidos o no en pareja, y familias constituidas por personas que mantienen una fuerte amistad, pero que no son pareja (Rice, 1997).

Esta diversificación progresiva de la familia como institución social trae seguramente cambios importantes en la forma como padres e hijos se 
relacionan y en las distintas modalidades de educación que experimentan los niños. También respecto a esto existe un considerable debate. Se afirma, por ejemplo, que las familias de hoy son más democráticas que las de antes, y en ellas los niños tendrían mayor oportunidad de participar en las decisiones que les competen, lo que les permitiría desarrollar, por tanto, criterio y autonomía desde épocas tempranas de la vida (Beck, 2002).

Algunos, no obstante, interpretan esta aparente democracia de la familia como una pérdida de autoridad de los padres. Éstos están tan atareados con las presiones a que los somete la sociedad actual, que prestan menos atención efectiva a sus hijos, por lo que los conocen menos, todo lo cual incrementa la inseguridad frente al ejercicio de su función parental (Flecha \& Tortajada, 1999). Así, bajo estas condiciones, los hijos estarían relativamente abandonados a sí mismos y tomando decisiones para las que no están aún preparados.

Antúnez (2001) sostiene que esta permisividad de los padres obedece también, en parte, a una confusión frente a los valores que sustentan su propia existencia y que estarían en crisis como resultado de la constante presión de la sociedad de consumo hacia el cambio. En consecuencia:

[...] dudan de su autoridad o temen ejercerla, en buena medida porque carecen de convicciones firmes y porque han sido alcanzados por el oleaje relativista, según el cual cada uno tiene su propia verdad. Al tenor de un estilo de vida como el que se va imponiendo, donde más que tener lo que todavía no se tiene, se trata de probar lo que todavía no se ha probado, los límites que se atreve a establecer la autoridad paterna se tornan cada vez más difusos y, cuando los hay, provienen de razones de seguridad o insuficiencia de recursos en relación con lo apetecido, pero no de principios (p. 22).

¿Y qué decir del afecto y el trato respetuoso que deben recibir los niños en su familia? También con respecto a esto las opiniones están divididas. Generalmente se acepta que en la sociedad actual se ha alcanzado una conciencia superior sobre las necesidades y los derechos de los niños. Esto se refleja en el surgimiento de disciplinas científicas y de profesiones que se ocupan exclusivamente de la infancia. Además, ha habido una evolución significativa de los pactos de derechos, los planes de acción y los instrumentos legislativos orientados a promover mejores condiciones de bienestar para todos los niños del planeta (Torrado, 2007). Todo esto ha permeado seguramente a la familia, por lo que el trato que los padres dan a sus hijos ha de ser más afectuoso y más respetuoso de sus derechos.

No obstante, en este punto nos tropezamos de nuevo con las fuertes contradicciones que están implícitas en el proceso de globalización. Si un número cada vez mayor de familias ve lesionados sus derechos a la educación, el trabajo y a tener una vida digna sin sufrir discriminaciones por motivo de raza o procedencia social, cultural o religiosa, entre otros, ¿cómo podemos esperar que en su interior se respeten los derechos de los niños y se les dispense un trato lo más afectuoso posible? Otra vez, nos vemos impelidos a indagar en los distintos niveles socioeconómicos para rastrear allí los cambios diferenciales que pueden estar ocurriendo.

Algunos autores hablan del abandono relativo a que están expuestos muchos niños de las clases media y alta, como resultado de la necesidad sentida por los padres de pasar más horas de su vida dedicados al trabajo o a actividades sociales. Estos niños estarían siendo "criados" por cuidadores sustitutos o, en el peor de los casos, pasarían muchas horas expuestos a la acción incontrolada e indiscriminada de los medios de comunicación, principalmente la televisión.

En el caso de los niños de clase baja, al abandono psicológico se sumaría eventualmente el abandono físico y material. Muchos de estos niños crecen en medio de grandes privaciones y un número considerable de ellos se ven obligados desde muy pequeños a trabajar para contribuir al sustento de su familia, viendo lesionados así, en forma total o parcial, sus derechos al juego, la recreación y la educación (Jaramillo, 1998). ¿Qué consecuencias se derivan de 
esto para su desarrollo físico, afectivo, intelectual y moral? ¿Cómo se afectan las relaciones en la familia?

Los estudios sobre los efectos de la pobreza han documentado las desventajas que enfrentan los niños que crecen bajo condiciones de privación extrema. Una de las conclusiones más importante es que en condiciones de pobreza aumenta la probabilidad de que las personas adultas con quienes conviven los niños estén sometidas a niveles altos de estrés, frustración o desesperanza, que las predisponen a recurrir más al maltrato físico o psicológico en sus prácticas educativas y a no brindar a los niños el cuidado y la estimulación que requieren para acceder a un desarrollo emocional e intelectual adecuado (Coulton, Korbin, Su \& Chow, 1995).

Las madres jóvenes cabeza de familia que no cuentan con una red de apoyo social y experimentan gran incertidumbre económica constituyen un grupo de alto riesgo. A veces caen en la depresión y esto suele tener consecuencias muy nocivas para los niños que están a su cargo, por el abandono a que éstos quedan expuestos (Kershner \& Cohen, 1992).

Todo esto nos conduce de nuevo al tema de la inclusión y la exclusión social que parece tener una gran relevancia cuando intentamos comprender la forma como la globalización se relaciona con cambios en los procesos interactivos dentro de la familia. Concretamente, observamos que las presiones a que se encuentra expuesto el grupo familiar son diferentes, dependiendo del grado de inclusión de que goce en la sociedad globalizada. La inclusión estaría dada no sólo por el nivel de ingresos económicos, sino también por la vinculación a una red de apoyo social que garantice la provisión de los recursos mínimos necesarios en periodos de crisis, conflicto o precariedad (Cohen \& Wills, 1985).

\section{La situación de la escuela}

Una institución social que brinda un apoyo importante a la familia, complementándola en sus funciones, es la escuela. También ella se encuentra sometida a fuertes presiones y cambios en la época actual, dado que tradicionalmente se le ha asignado como función principal la de transmitir a las nuevas generaciones de seres humanos el conocimiento desarrollado por la cultura a través de la historia.

Este conocimiento es hoy tan amplio, diverso, especializado y cambiante, que la escuela se encuentra con el inmenso desafío de redefinir definitivamente su rol, o por lo menos, desarrollar nuevas metodologías a través de las cuales se prepare a los nuevos ciudadanos para aprender con efectividad cuando requieran hacerlo, saber cómo buscar y seleccionar aquellos conocimientos que les servirán para integrarse exitosamente en la sociedad global y alcanzar el ingenio y la creatividad suficientes para contribuir luego en alguna medida a la construcción de nuevos conocimientos (De Zubiría, 2003).

Un componente crucial de la experiencia escolar es la calidad de la relación que se establece entre el profesor y los estudiantes. En nuestro caso, ¿cómo se involucra el profesor en el proceso de aprendizaje del niño? ¿Qué claridad tiene sobre las metas de su trabajo? ¿Hasta qué punto logra descifrar sus conocimientos implícitos, sus sentimientos, sus aptitudes y rasgos de personalidad, para integrarlos creativamente en la relación pedagógica? ¿Qué tan eficaz es el trabajo en equipo de profesores y padres de familia para promover el desarrollo de los niños? Todas estas preguntas nos remiten directa o indirectamente a la calidad de la mediación que realiza el docente al introducir al niño en el patrimonio intelectual de su cultura, así como al grado de visibilidad que alcanzan los niños en este proceso. ¿Es la escuela un lugar donde se reconocen y aplican los derechos de los niños? ¿Respetan los estándares de calidad que impone la sociedad globalizada a la escuela los derechos fundamentales de los niños?

Al respecto, Bernal (2009) afirma "Cualquier niño está en capacidad de decir con qué tipo de profesor aprende más, cuáles son las características de ese maestro, cómo le gustaría que fuera su escuela, cómo le gustaría que lo trataran, e inclusive 
qué lo puede hacer feliz en la escuela" (p. 11). Pero los patrones de calidad que se están utilizando en la escuela actual con frecuencia parecen no tomar en consideración el punto de vista de los niños y ni siquiera el de su cultura local. Son patrones establecidos internacionalmente y que provienen de los países que ostentan una posición dominante en el ámbito de la economía y la ciencia. La calidad llega a entenderse así como la capacidad de la escuela para preparar individuos que sirvan a los intereses de los centros de poder en el mundo globalizado (Torres \& Morrow, 2005). $Y$ aquí interviene nuevamente la estratificación.

No habría recursos para que todos accedan en igualdad de condiciones a una educación de calidad. Prueba de esto son miles de escuelas en las que 45, 50 o más niños aprenden apiñados en un pequeño salón, con un mínimo de materiales pedagógicos y sin apenas tener la oportunidad de mantener un contacto personal con el profesor, o escuelas en las que un grupo muy heterogéneo de niños, pertenecientes a distintos niveles de escolaridad, aprenden simultáneamente con un profesor, dada la escasez de recursos humanos, locativos y didácticos. Estas escuelas, que son a las que asisten usualmente los niños de los sectores socioeconómicos de bajos ingresos o de las áreas rurales, se quedarían por fuera en el cumplimiento de los criterios de calidad, motivo por el cual la mayoría de sus estudiantes pasarían a ocupar luego una posición subordinada y desventajosa en el conjunto de la sociedad.

Por lo anterior, esta investigación se orientó a ampliar la comprensión sobre los significados que están construyendo los niños, padres de familia y profesores sobre la infancia, la familia y la escuela en el contexto urbano de la ciudad de Bogotá y dentro del marco más general de una sociedad que se encuentra cada vez más involucrada en los procesos de globalización. Se esperaba que el estudio de los significados expresados por los niños, padres de familia y profesores aportara pistas para entender mejor cómo están cambiando las interacciones en la familia y la escuela y qué transformaciones están teniendo lugar en los procesos de desarrollo infantil.
Para la recolección de información se aplicaron encuestas y se realizaron escenarios conversacionales. En este artículo, nos ocupamos exclusivamente de la descripción y el análisis de los resultados obtenidos a través de la encuesta. Los resultados obtenidos en los escenarios conversacionales serán publicados en otro artículo que se encuentra en proceso de elaboración.

\section{Método}

\section{Población}

Niños y niñas de 9 a 11 años, padres de familia y profesores vinculados a la educación elemental en instituciones educativas de estratos 1, 2, 3 y 4 de la ciudad de Bogotá.

\section{Participantes}

En el estudio participaron 73 niños y niñas, 52 padres de familia y 52 profesores. Todos fueron abordados en las instituciones educativas a las que estaban vinculados en su condición de estudiantes, padres de familia o profesores. Los niños y niñas tenían edades entre los 9 y 11 años y se encontraban cursando los grados $4^{\circ}$ o $5^{\circ}$ elemental. Los padres de familia tenían uno o más hijos estudiando y los profesores trabajaban en la sección de primaria de las instituciones educativas investigadas.

Tres instituciones educativas pertenecían a los estratos socioeconómicos 1 y 2 y tres eran representativas de los estratos socioeconómicos 3 y 4. El criterio utilizado para esta estratificación fue el monto de la pensión que pagaban mensualmente los estudiantes. Si la pensión era inferior a $\$ 200.000$ pesos mensuales, se consideró a la institución como perteneciente a los estratos 1 y 2 . Si el monto de la pensión fluctuaba entre $\$ 200.000$ y 500.000 se consideró como perteneciente a los estratos socioeconómicos 3 y 4 . Por limitaciones de tiempo y de acceso a la información no se incluyeron en este estudio instituciones educativas de los estratos socioeconómicos 5 y 6 . 


\section{Procedimiento}

El instrumento elegido para la recolección de la información pertinente fue la encuesta. Ésta se elaboró de tal manera que se preguntaba lo mismo a los niños y niñas, a los padres de familia y a los profesores, pero en el caso de los niños, la introducción general a las preguntas era diferente y las opciones de respuesta a elegir eran más simples.

Así, mientras los padres de familia o los profesores tenían que elegir entre 4 opciones de respuesta diferentes, los niños elegían entre tres. Éstas fueron las opciones de respuesta para cada pregunta planteada a los padres y profesores: Totalmente en desacuerdo / En desacuerdo/ De acuerdo / Totalmente de acuerdo. Las opciones de respuesta para los niños y niñas fueron: No / No sé / Sí.

En la introducción a las preguntas formuladas a los padres de familia y los profesores se les pedía hacer una comparación de los niños, padres de familia y profesores de antes con los niños, padres de familia y profesores de ahora. Esta comparación no se les pidió a los niños, debido a que se asumió que carecían de la experiencia necesaria para realizarla.

En la Tabla 1 se presenta la instrucción general que se dio tanto a los niños, como a los padres de familia y los profesores, para que respondieran a la encuesta, tomando como referencia el contexto general de la globalización, mientras que en la Tabla 2 están los ítems de la encuesta que se aplicó a los tres grupos de sujetos.

Tabla 1. Introducción a la encuesta

\footnotetext{
En este cuestionario encontrarás preguntas acerca de la infancia, la familia y el colegio en el mundo actual. Nos interesa conocer tu opinión sobre la forma como los niños viven, lo que sienten, desean o piensan, cómo se relacionan con sus padres en la familia y con sus profesores en la escuela. No hay respuestas buenas o malas. En realidad la mejor respuesta es la que muestra con exactitud lo que tú percibes o piensas.
}

Mientras respondes a las preguntas piensa en aquello que hace característico al mundo de hoy. La televisión, los computadores, el Internet, los teléfonos celulares y otras tecnologías que facilitan enormemente la comunicación entre las personas y los países. Hay más negocios internacionales y podemos conocer mejor cómo vive la gente en otros lugares de la tierra. Existen los grandes supermercados, en los que puedes comprar mil cosas diferentes. Sin embargo, muchos no tienen el dinero para comprar aquello que necesitan o desearían tener. Además, las cosas que se compran se vuelven anticuadas pronto, ya que aparecen nuevas cosas que son más atractivas o prometen ser mucho mejores.

¿Cómo actúan los niños frente a estos cambios que están ocurriendo en el mundo? ¿Qué significado tienen para ellos? ¿Cómo experimentan los padres y los profesores estos cambios? ¿De qué manera se reflejan en la forma como educan a sus hijos y a sus estudiantes?

Tabla 2. Contenido de la encuesta

\begin{tabular}{ll}
\hline ÍTEMS DE LA ENCUESTA & \\
\hline \multirow{2}{*}{ Versión niños } & $\begin{array}{l}\text { Versión padres de familia y pro- } \\
\text { fesores }\end{array}$ \\
Opciones de respuesta & Opciones de respuesta: \\
Sí & Totalmente en desacuerdo \\
No sé & En desacuerdo \\
No & De acuerdo \\
& Totalmente de acuerdo
\end{tabular}

Los niños de ahora... (versión niños)

Los niños de hoy comparados con los niños de antes: (versión padres y profesores)

1 ... Son más veloces para aprender

2... Soportan con mayor facilidad frustraciones

3... Necesitan menos la guía de sus padres

4... Hacen amigos más fácilmente

5... Logran controlar mejor sus emociones

6... Gozan de vínculos afectivos más fuertes

7... Conocen mejor sus derechos

8... Cumplen más estrictamente con sus deberes

9... Llegan a saber más pronto qué es lo que quieren

10 ... Logran niveles de concentración más altos

$11 .$. Llegan a estar preparados más pronto para afrontar las responsabilidades de la vida adulta

12... Son más felices

13... Son más autónomos

14... Logran comprender mejor el punto de vista de los demás

15... Saben más sobre el mundo que los rodea

16... Se muestran más recursivos para resolver los problemas de la vida diaria

17... Son más disciplinados

18... gozan de mejor salud física

19... Tienen mejores modales

20... Son más hábiles para defender su punto de vista

21... Tienen mejor memoria*

22... Sufren más de problemas emocionales

23... Son más respetuosos con los adultos

$24 . .$. Entienden mejor los valores de convivencia

*Esta pregutna no se le hizo a los niños 
Los padres de ahora...(versión niños)

Los padres de hoy comparados con los padres de antes...

(versión padres y profesores)

1... Tienen más claro cómo educar a sus hijos

2... Comparten más tiempo con ellos

3... Los apoyan más con sus deberes escolares

4... Los protegen con mayor cuidado de peligros

5... Los miman más

6... Les brindan más afecto

7... Les enseñan más sobre lo que saben

8... Logran comprender mejor sus sentimientos

9... Adivinan más fácilmente lo que ellos piensan

10... Les brindan más reconocimiento

11... Los castigan menos

12... Respetan más sus derechos

13... Les ofrecen más oportunidades de desarrollo

14... Dialogan más con ellos

15... Les imponen más prohibiciones

16... Los acompañan más en momentos importantes de su vida

Los profesores de ahora... (versión niños)

Los profesores de hoy comparados con los profesores de antes...(versión padres y profesores)

1 ... Tienen más claro cómo orientar a sus estudiantes

2... Muestran más compromiso para apoyarlos

3... Los tratan más afectuosamente

4... Comprenden mejor sus sentimientos

5... Están más actualizados en sus conocimientos

6... Tienen una mejor preparación en pedagogía

7... Respetan más la personalidad de cada estudiante

8... Reconocen mejor las aptitudes de cada uno

9... Tienen una actitud más justa al corregirlos

10... Muestran más disposición para dialogar con ellos

11... Respetan más sus derechos

12... Fomentan más la cooperación en el aula

13... Ayudan más al estudiante con dificultades

14... Logran trabajar mejor en equipo con los padres

Todos los ítems de la encuesta estuvieron orientados a indagar sobre los significados que asocian los niños, padres de familia y profesores con la infancia y con las interacciones que tienen lugar en contextos familiares y escolares, en la actualidad.

\section{Resultados}

Al analizar los resultados obtenidos en los ítems relacionados con significados en torno a la infancia en la actualidad, observamos las siguientes tendencias (Tabla 3):
Varios ítems se refieren al desarrollo cognitivo de los niños de hoy, comparados con los niños de antes. La mayoría de los niños, padres de familia y profesores coinciden en que los niños de hoy son particularmente veloces para aprender. Esta característica es resaltada con mayor intensidad por los padres que por los profesores.

En lo que se refiere a la capacidad de concentración que manifiestan los niños, las posiciones de los tres grupos de participantes tienden a ser diferentes. Los niños en su mayoría creen alcanzar altos niveles de concentración. Los puntos de vista de los padres al respecto están divididos: algunos piensan que los niños de hoy son más concentrados y otros que no. Por su parte, los maestros se inclinan a pensar que los niños en la actualidad no logran niveles de concentración más altos que los niños de antes.

Encontramos también diferencias entre los padres y maestros en la forma de juzgar la memoria de los niños. Mientras los padres tienden a pensar que los niños tienen hoy mejor memoria que antes, los maestros se inclinan a estar en desacuerdo con esta afirmación.

Por último, tanto los niños, como los padres de familia y los profesores tienden a resaltar el conocimiento que demuestran los niños sobre el mundo que los rodea. Estos últimos creen saber mucho sobre aquel, mientras que los padres y profesores se inclinan a pensar que, en este punto, los niños de ahora superan claramente a los de antes.

Idéntica tendencia se observa frente al ítem en el que se pregunta si los niños de hoy son más recursivos para resolver los problemas de la vida diaria. 
Tabla 3. Significados acerca de la infancia: desarrollo cognitivo

\begin{tabular}{|c|c|c|c|c|c|c|c|c|c|c|c|}
\hline \multirow[b]{2}{*}{ ÍTEMS } & \multicolumn{3}{|c|}{ Niños } & \multicolumn{4}{|c|}{ Padres de familia } & \multicolumn{4}{|c|}{ Profesores } \\
\hline & $N$ & N.S. & $S$ & T.D. & D & A & T.A. & T.D. & D & A & T.A. \\
\hline $\begin{array}{l}\text { Velocidad para } \\
\text { aprender }\end{array}$ & 12.3 & 26 & 61.6 & 3.9 & 2.0 & 37.3 & 56.9 & 5.9 & 5.9 & 64.7 & 23.5 \\
\hline Concentración & 24.7 & 17.8 & 57.5 & 12 & 38 & 34 & 16 & 25 & 53.8 & 21.2 & 0.0 \\
\hline Memoria & & & & 10 & 22 & 36 & 32 & 17.6 & 45.1 & 31.4 & 5.9 \\
\hline Conocimiento & 16.4 & 16.4 & 67.1 & 0.0 & 8.2 & 44.9 & 46.9 & 3.8 & 13.5 & 51.9 & 30.8 \\
\hline Recursividad & 17.8 & 16.4 & 65.8 & 4 & 28 & 46 & 22 & 7.7 & 32.7 & 50 & 9.6 \\
\hline
\end{tabular}
$\begin{array}{llll}\text { N: No N.S.: No sé } & \text { S: Sí } & \text { T.D: Totalmente en desacuerdo } & \text { D: En desacuerdo } \\ \text { A: De acuerdo } & \text { T.A: } \text { Totalmente de acuerdo. } & \end{array}$

Otros ítems estaban orientados a analizar el desarrollo emocional de los niños, tal como es contemplado por los distintos grupos participantes en la encuesta (Tabla 4). Todos ellos se inclinan a poner en duda la disposición de los niños de hoy a soportar frustraciones.

Respecto a la capacidad que demuestran los infantes para controlar sus emociones, tanto los juicios de los niños encuestados como los de los padres, están divididos. Los maestros, en cambio, tienden a estar en desacuerdo con la afirmación de que los niños hoy logran mejor control de sus emociones que los niños de antes.

Tampoco creen que los vínculos afectivos que construyen en la actualidad sean más fuertes que los que construían antes. Frente a esta pregunta los padres están nuevamente divididos, y los niños en su mayoría si creen gozar de vínculos afectivos fuertes.

En lo que se refiere a la felicidad que experimentan los niños en la actualidad, el perfil de las respuestas fue muy parecido al de la pregunta ante- rior: es decir, niños que tienden a creer que los niños de hoy son felices, padres que están divididos en sus respuestas y profesores que no creen que los niños de ahora sean más felices que los de antes.

Este mismo patrón de respuestas se observó también frente a la pregunta acerca de si los niños de hoy están preparados más pronto para afrontar las responsabilidades de la vida diaria. Aquí nuevamente resalta la respuesta negativa de los docentes.

Una pregunta complementaria de ésta era si los niños en la actualidad llegan a saber más pronto qué es lo que quieren: los niños y los padres de familia se inclinaron a responder positivamente, mientras que los profesores respondieron en el sentido contrario.

Por último, observamos que los tres grupos de participantes tienden a coincidir en la afirmación de que los niños de hoy sufren de problemas emocionales $\mathrm{y}$, según los padres y profesores, más que los niños de antes.

Tabla 4. Significados acerca de la infancia: desarrollo emocional

\begin{tabular}{|c|c|c|c|c|c|c|c|c|c|c|c|}
\hline & \multicolumn{3}{|c|}{ Niños } & \multicolumn{4}{|c|}{ Padres de familia } & \multicolumn{4}{|c|}{ Profesores } \\
\hline Ítems encuesta & $\mathrm{N}$ & N.S. & $S$ & T.D. & D & A & T.A. & T.D. & D & $A$ & T.A. \\
\hline $\begin{array}{l}\text { Tolerancia de } \\
\text { frustraciones }\end{array}$ & 68.5 & 13.7 & 17.8 & 10 & 52 & 30 & 8 & 17.3 & 61.5 & 17.3 & 3.8 \\
\hline $\begin{array}{l}\text { Control de } \\
\text { emociones }\end{array}$ & 37 & 21.9 & 41.1 & 3.9 & 45.1 & 45.1 & 5.9 & 19.6 & 68.6 & 9.8 & 2.0 \\
\hline $\begin{array}{l}\text { Vínculos afecti- } \\
\text { vos fuertes }\end{array}$ & 19.2 & 17.8 & 63 & 10.2 & 36.7 & 42.9 & 10.2 & 29.4 & 47.1 & 19.6 & 3.9 \\
\hline Felicidad & 9.6 & 19.2 & 71.2 & 8.2 & 36.7 & 44.9 & 10.2 & 13.5 & 63.5 & 21.2 & 1.9 \\
\hline
\end{tabular}




\begin{tabular}{lccccccccccc}
\hline & \multicolumn{3}{c}{ Niños } & \multicolumn{3}{c}{ Padres de familia } & \multicolumn{5}{c}{ Profesores } \\
\hline $\begin{array}{l}\text { Asunción de res- } \\
\text { ponsabilidades }\end{array}$ & 22.2 & 16.7 & 61.1 & 12 & 32 & 46 & 10 & 17.3 & 51.9 & 28.8 & 1.9 \\
$\begin{array}{l}\text { Saber lo que se } \\
\text { quiere }\end{array}$ & 15.1 & 13.7 & 71.2 & 10 & 20 & 44 & 26 & 13.5 & 46.2 & 26.9 & 13.5 \\
$\begin{array}{l}\text { Problemas emo- } \\
\text { cionales }\end{array}$ & 28.8 & 21.9 & 49.3 & 2 & 34 & 34 & 30 & 3.8 & 19.2 & 28.8 & 48.1 \\
\hline
\end{tabular}

N: No N.S.: No sé A: De acuerdo

S: Sí

T.A: Totalmente de acuerdo

Un tercer grupo de ítems estaba orientado a observar el grado en que los niños logran integrarse armónicamente en sus grupos de referencia ( $\mathrm{fa}$ milia, escuela y amigos) afirmando sus derechos y respondiendo adecuadamente a las expectativas y demandas que se dirigen a ellos (Tabla 5).

Los tres grupos de participantes tienden a coincidir en que los niños de hoy hacen fácilmente amigos y en este sentido superan a los niños de antes.

Concuerdan también en rechazar la afirmación de que los niños en la actualidad necesitan menos la guía de sus padres, pero están de acuerdo en que ahora son más autónomos que antes.

Alrededor de la mitad de los niños piensa que los niños hoy tienen buenos modales y son respetuosos con las personas adultas. Los padres y profesores tienden a oponerse a estas afirmaciones puntualizando que ni los modales ni el respeto hacia las personas adultas son mejores ahora que antes. La misma posición expresan frente al cumplimiento de deberes y la disciplina de los niños: no serían mejores ahora que antes. En los anteriores puntos, los profesores muestran consistentemente posiciones más unificadas que las de los padres.
Los tres grupos de participantes coinciden en que los niños hoy conocen bien sus derechos y son hábiles para defender su punto de vista. En estos aspectos estarían más avanzados que los niños de antes (según padres y profesores).

En lo que se refiere a la capacidad de comprender el punto de vista de los otros, las opiniones de niños y padres de familia, por un lado, y de profesores, por el otro, tienden a ser contradictorias. Los niños tienden a atribuirse a sí mismos una buena capacidad para comprender a los otros, los padres creen que esta capacidad está más desarrollada en los niños de hoy que en los de antes y los profesores piensan en el sentido contrario.

Esta misma tendencia se manifiesta en relación con la última pregunta sobre la capacidad de entender los valores de convivencia. Nuevamente son los profesores quiénes manifiestan con mayor frecuencia dudas al respecto.

En términos generales, los niños perciben en sí mismos un buen estado de salud, los padres tienden a estar divididos en sus puntos de vista al respecto y los profesores se inclinan a dudar del buen estado de salud de los niños.

Tabla 5. Significados acerca de la infancia: aspectos de socialización

\begin{tabular}{lccccccccccc}
\hline & & Niños & \multicolumn{1}{c}{ Padres de familia } & \multicolumn{5}{c}{ Padres de familia } \\
\hline \multicolumn{1}{c}{ Ítems encuesta } & N & N.S. & S & T.D. & D & A & T.A. & T.D. & D & A & T.A. \\
$\begin{array}{l}\text { Hacer fácilmente } \\
\text { amigos }\end{array}$ & 16.7 & 9.7 & 73.6 & 10 & 14 & 40 & 36 & 7.8 & 19.2 & 42.3 & 32.7 \\
$\begin{array}{l}\text { Necesitar menos guía } \\
\text { de padres }\end{array}$ & 59.7 & 9.7 & 30.6 & 30 & 38 & 30 & 2 & 44.2 & 28.8 & 21.2 & 5.8 \\
$\begin{array}{l}\text { Tener buenos } \\
\text { modales }\end{array}$ & 29.6 & 28.2 & 42.3 & 22 & 44 & 24 & 10 & 42.3 & 46.2 & 5.8 & 5.8 \\
$\begin{array}{l}\text { Ser respetuoso con } \\
\text { adultos }\end{array}$ & 24.7 & 16.4 & 58.9 & 22 & 62 & 10 & 6 & 36.5 & 51.9 & 5.8 & 5.8 \\
$\begin{array}{l}\text { Cumplimiento estricto } \\
\text { de deberes }\end{array}$ & 31.5 & 31.5 & 37 & 9.8 & 47.1 & 37.3 & 5.9 & 25.5 & 64.7 & 9.8 & 0 \\
\hline
\end{tabular}




\begin{tabular}{|c|c|c|c|c|c|c|c|c|c|c|c|}
\hline \multirow[b]{2}{*}{ Ser disciplinado } & \multicolumn{3}{|c|}{ Niños } & \multicolumn{4}{|c|}{ Padres de familia } & \multicolumn{4}{|c|}{ Padres de familia } \\
\hline & 41.7 & 23.6 & 34.7 & 11.8 & 51 & 33.3 & 3.9 & 36.5 & 51.9 & 9.6 & 1.9 \\
\hline $\begin{array}{l}\text { Conocer derechos } \\
\text { propios }\end{array}$ & 12.3 & 13.7 & 74 & 0 & 2 & 32 & 66 & 1.9 & 11.5 & 57.7 & 28.8 \\
\hline $\begin{array}{l}\text { Defender puntos de } \\
\text { vista propios }\end{array}$ & 8.2 & 24.7 & 67.1 & 0 & 2 & 36 & 62 & 1.9 & 17.3 & 46.2 & 34.6 \\
\hline $\begin{array}{l}\text { Entender valores } \\
\text { convivencia }\end{array}$ & 16.4 & 17.8 & 65.8 & 8 & 24 & 48 & 20 & 19.2 & 57.7 & 21.2 & 1.9 \\
\hline
\end{tabular}

La segunda parte de la encuesta estaba dirigida a indagar sobre los significados que los niños, padres de familia y profesores reflejan frente a la forma como los padres interactúan hoy con los niños, comparados con los padres de antes. Los resultados que arroja esta parte de la encuesta son los siguientes (Tabla 6):

Los niños en su mayoría piensan que los padres tienen claro cómo educarlos y los padres se inclinan a pensar que en la actualidad existe más claridad sobre cómo educar a los hijos. Entre los profesores, prima el punto de vista contrario.

En cuanto al tiempo que comparten los padres con sus hijos, las opiniones de los niños están divididas. Unos piensan que comparten bastante tiempo con ellos, otros que no. La mayoría de los padres y profesores no cree que los padres compartan ahora más tiempo con sus hijos.

Los niños, en general, coinciden en afirmar que los hijos reciben un apoyo escolar adecuado de sus padres. Las opiniones de los padres sobre si esto es mejor hoy que antes, están divididas y los profesores se inclinan a pensar que no es mejor hoy que antes.

En cuanto a la protección frente a los peligros, nuevamente los puntos de vista de los padres de familia y los de los niños tienden a coincidir. Los niños resaltan que los padres los protegen con mucho cuidado de los peligros, los padres se inclinan a pensar que la protección para los niños es hoy mayor que antes y los profesores están divididos en su forma de pensar frente a esto.

La mayoría de los niños piensa que los padres dialogan con sus hijos, logran comprender sus sentimientos, los acompañan en momentos importantes de su vida y les enseñan mucho sobre lo que saben. Los padres tienden a confirmar estas apreciaciones, conceptuando que esto se da hoy más que antes. Los profesores tienden a mostrarse escépticos frente a las tres primeras apreciaciones y frente a la última, sus puntos de vista están divididos.

Los tres grupos de participantes se inclinan a aceptar que los niños en la actualidad son mimados y que lo son hoy más que antes (padres y profesores). También coinciden en que se les castiga menos que antes y en que sus padres respetan más sus derechos y les brindan más oportunidades de desarrollo. Los padres y profesores tienden a estar además de acuerdo en que a los niños en la actualidad no se les imponen más prohibiciones que a los niños de antes.

La inmensa mayoría de los niños está de acuerdo en que los padres les brindan afecto y reconocimiento. Los padres se inclinan a pensar que los niños de hoy reciben más afecto y reconocimiento que los de antes, mientras que las opiniones de los profesores están divididas, tendiendo a estar más de acuerdo con el reconocimiento y menos con el afecto brindado por los padres. 
Tabla 6. Significados acerca de la familia: ¿cómo interactúan los padres con los niños?

\begin{tabular}{|c|c|c|c|c|c|c|c|c|c|c|c|}
\hline & \multicolumn{3}{|c|}{ Niños } & \multicolumn{4}{|c|}{ Padres de familia } & \multicolumn{4}{|c|}{ Profesores } \\
\hline Ítems encuesta & $\mathrm{N}$ & N.S. & $\mathrm{S}$ & T.D. & D & $A$ & T.A. & T.D. & D & $A$ & T.A. \\
\hline $\begin{array}{l}\text { Claridad sobre cómo } \\
\text { educar }\end{array}$ & 5.5 & 9.6 & 84.9 & 10 & 22 & 46 & 22 & 23.1 & 55.8 & 17.3 & 3.8 \\
\hline $\begin{array}{l}\text { Tiempo compartido con } \\
\text { los hijos }\end{array}$ & 39.7 & 19.2 & 41.1 & 22.4 & 49 & 22.4 & 6.1 & 48.1 & 46.2 & 3.8 & 1.9 \\
\hline $\begin{array}{l}\text { Apoyo a hijos en deberes } \\
\text { escolares }\end{array}$ & 5.5 & 5.5 & 89 & 10 & 38 & 36 & 16 & 28.8 & 53.8 & 13.5 & 3.8 \\
\hline $\begin{array}{l}\text { Protección frente a los } \\
\text { peligros }\end{array}$ & 0 & 4.1 & 95.9 & 6 & 26 & 44 & 24 & 19.2 & 28.8 & 42.3 & 9.6 \\
\hline Diálogo con los hijos & 13.7 & 9.6 & 76.7 & 10.2 & 28.6 & 36.7 & 24.5 & 19.2 & 53.8 & 23.1 & 3.8 \\
\hline $\begin{array}{l}\text { Comprensión sentimientos } \\
\text { de los hijos }\end{array}$ & 19.2 & 11 & 69.9 & 4.1 & 28.6 & 49 & 18.4 & 11.5 & 57.7 & 26.9 & 3.8 \\
\hline $\begin{array}{l}\text { Acompañamiento en } \\
\text { momentos importantes }\end{array}$ & 4.1 & 6.8 & 89 & 10 & 20 & 40 & 30 & 19.6 & 47.1 & 33.3 & 0 \\
\hline Mimos a los hijos & 15.1 & 11 & 74 & 2 & 16 & 54 & 28 & 7.7 & 26.9 & 40.4 & 25 \\
\hline Poco castigo a los hijos & 20.5 & 17.8 & 61.6 & 4.2 & 6.3 & 56.3 & 33.3 & 3.8 & 17.3 & 59.6 & 19.2 \\
\hline $\begin{array}{l}\text { Respeto a los derechos de } \\
\text { los hijos }\end{array}$ & 2.7 & 9.6 & 87.7 & 2 & 12.2 & 59.2 & 26.5 & 9.6 & 16.2 & 63.5 & 7.7 \\
\hline $\begin{array}{l}\text { Brindar oportunidades de } \\
\text { desarrollo a los hijos }\end{array}$ & 4.1 & 9.6 & 86.3 & 2 & 8.2 & 46.9 & 42.9 & 1.9 & 26.9 & 55.8 & 15.4 \\
\hline $\begin{array}{l}\text { Imposición de } \\
\text { prohibiciones }\end{array}$ & 13.7 & 15.7 & 71.2 & 14.3 & 44.9 & 30.6 & 10.2 & 19.6 & 49 & 25.5 & 5.9 \\
\hline $\begin{array}{l}\text { Provisión de afecto a los } \\
\text { hijos }\end{array}$ & 1.4 & 2.8 & 95.8 & 8.2 & 24.5 & 55.1 & 12.2 & 11.8 & 49 & 35.3 & 3.9 \\
\hline Reconocimiento a los hijos & 2.7 & 9.6 & 87.7 & 2 & 18.4 & 51 & 28.6 & 7.7 & 32.7 & 48.1 & 11.5 \\
\hline $\begin{array}{l}\text { Adivinación de } \\
\text { pensamientos de los hijos }\end{array}$ & 38.9 & 20.8 & 40.3 & 10.2 & 38.8 & 40.8 & 10.2 & 11.5 & 55.8 & 30.8 & 1.9 \\
\hline $\begin{array}{l}\text { Enseñar a los hijos sobre } \\
\text { lo que saben }\end{array}$ & 4.2 & 11.1 & 84.7 & 6 & 22 & 50 & 22 & 9.6 & 42.3 & 42.3 & 5.8 \\
\hline
\end{tabular}
N: No N.S.: No sé
A: De acuerdo
S: Sí T.D. Totalmente en desacuerdo
D: En desacuerdo

La tercera parte de la encuesta estuvo dirigida a estudiar los significados que los niños, padres de familia y profesores manifiestan frente a la forma como los profesores interactúan hoy con los niños en el contexto escolar, comparados con los profesores de antes. Los resultados obtenidos se describen a continuación (Tabla 7):

En la mayoría de los ítems los niños tienden a valorar positivamente la forma como los profesores interactúan con ellos. Más del $60 \%$ de los niños piensa que los profesores tienen claridad sobre la forma de orientar a sus estudiantes, y que son comprometidos en el apoyo que les brindan. Piensan además que están actualizados en sus conocimientos, que tienen buena preparación en pedagogía y que respetan y reconocen la persona- lidad y aptitudes de cada uno. También están de acuerdo en que respetan sus derechos, fomentan la cooperación en el aula, ayudan al estudiante con dificultades y logran trabajar bien en equipo con los padres de familia. Entre el 16 y el $26 \%$ de los niños no supo qué responder frente a estos ítems y entre el 4 y el $18 \%$ estuvo en desacuerdo con las anteriores afirmaciones.

En otros ítems, el grado de acuerdo entre los niños estuvo alrededor del $50 \%$. Estos ítems eran los referentes al trato afectuoso de parte de los profesores, la actitud justa al corregirlos y el diálogo con los estudiantes. Por último, en el ítem No. 4, que hacía referencia a la capacidad de los profesores para entender los sentimientos de los estudiantes, tendió a primar la respuesta negativa. 
Los padres y los profesores también muestran en general una valoración positiva de la forma como los profesores interactúan con los niños en el contexto escolar. En todos los ítems, tanto los padres como los profesores tendieron a estar de acuerdo en que los profesores de hoy, comparados con los profesores de antes, tienen más claridad sobre cómo orientar a sus estudiantes, son más comprometidos para apoyarlos, los tratan más afectuosamente, comprenden mejor sus senti- mientos, están más actualizados en sus conocimientos, muestran más preparación pedagógica, respetan más la personalidad de cada estudiante, reconocen más sus aptitudes, tienen una actitud más justa al corregirlos, dialogan más con ellos, respetan más sus derechos, fomentan más la cooperación en el aula, ayudan más al estudiante con dificultades y logran trabajar mejor en equipo con los padres.

Tabla 7. Significados acerca de la escuela: ¿cómo interactúan los profesores con los niños?

\begin{tabular}{|c|c|c|c|c|c|c|c|c|c|c|c|}
\hline \multirow[b]{2}{*}{ Ítems encuesta } & \multicolumn{3}{|c|}{ Niños } & \multicolumn{4}{|c|}{ Padres de familia } & \multicolumn{4}{|c|}{ Profesores } \\
\hline & $\mathrm{N}$ & N.S. & $S$ & T.D. & D & $\mathrm{A}$ & T.A. & T.D. & D & $A$ & T.A. \\
\hline $\begin{array}{l}\text { Claridad para orientar a sus } \\
\text { estudiantes }\end{array}$ & 9.6 & 16.4 & 74 & 0 & 4.1 & 57.1 & 38.8 & 0 & 21.2 & 55.8 & 23.1 \\
\hline $\begin{array}{l}\text { Compromiso para apoyar a } \\
\text { estudiantes }\end{array}$ & 17.8 & 16.4 & 65.8 & 2 & 10.2 & 69.4 & 18.4 & 0 & 5.9 & 72.5 & 21.6 \\
\hline $\begin{array}{l}\text { Trato afectuoso hacia el } \\
\text { estudiante }\end{array}$ & 23.3 & 26 & 50.7 & 6 & 16 & 54 & 24 & 0 & 5.8 & 61.5 & 32.7 \\
\hline $\begin{array}{l}\text { Comprensión de sentimien- } \\
\text { tos del estudiante }\end{array}$ & 41.7 & 22.2 & 36.1 & 4.1 & 16.3 & 59.2 & 20.4 & 0 & 17.3 & 61.5 & 21.2 \\
\hline $\begin{array}{l}\text { Actualización en conoci- } \\
\text { mientos }\end{array}$ & 16.4 & 15.1 & 68.5 & 0 & 8.2 & 49 & 42.9 & 0 & 1.9 & 53.8 & 44.2 \\
\hline Preparación en pedagogía & 4.1 & 30.1 & 65.8 & 2 & 6.1 & 40.8 & 51 & 0 & 5.8 & 44.2 & 50 \\
\hline $\begin{array}{l}\text { Respeto a personalidad del } \\
\text { estudiante }\end{array}$ & 18.1 & 6.9 & 75 & 6.1 & 10.2 & 61.2 & 22.4 & 0 & 7.7 & 69.2 & 23.1 \\
\hline $\begin{array}{l}\text { Reconocimiento de aptitu- } \\
\text { des del estudiante }\end{array}$ & 13.7 & 19.2 & 67.1 & 0 & 12.2 & 75.5 & 12.2 & 0 & 7.7 & 69.2 & 23.1 \\
\hline $\begin{array}{l}\text { Actitud justa al corregir al } \\
\text { estudiante }\end{array}$ & 28.8 & 17.8 & 53.4 & 2 & 20.4 & 63.3 & 14.3 & 0 & 13.5 & 69.2 & 17.3 \\
\hline Disposición al diálogo & 27.4 & 21.9 & 50.7 & 2 & 18.4 & 65.3 & 14.3 & 0 & 1.9 & 67.3 & 30.8 \\
\hline $\begin{array}{l}\text { Respeto de los derechos del } \\
\text { estudiante }\end{array}$ & 5.5 & 20.5 & 74 & 2 & 8 & 64 & 26 & 0 & 3.8 & 73.1 & 23.1 \\
\hline $\begin{array}{l}\text { Fomento de la cooperación } \\
\text { en el aula }\end{array}$ & 12.3 & 23.3 & 64.4 & 0 & 2 & 77.6 & 20.4 & 0 & 7.7 & 71.2 & 21.2 \\
\hline $\begin{array}{l}\text { Ayuda al estudiante con difi- } \\
\text { cultades }\end{array}$ & 11 & 21.9 & 67.1 & 4.1 & 12.2 & 53.1 & 30.6 & 0 & 7.7 & 61.5 & 30.8 \\
\hline $\begin{array}{l}\text { Trabajo en equipo con pa- } \\
\text { dres }\end{array}$ & 17.8 & 17.8 & 64.4 & 2 & 16 & 56 & 26 & 9.6 & 25 & 44.2 & 21.2 \\
\hline
\end{tabular}

N: No N.S.: No sé A: De acuerdo
S: Sí

T.A: Totalmente de acuerdo
D: En desacuerdo
Cuando comparamos los resultados obtenidos en las instituciones escolares de estrato socioeconómico 1 y 2 con los obtenidos en las instituciones escolares de estrato socioeconómico 3 y 4 , encontramos lo siguiente:

Los niños de estratos socioeconómicos 1 y 2 difieren significativamente de los de estratos so- cioeconómicos 3 y 4 en varios de los significados expresados en torno a la infancia. En la Tabla 8 se presentan los ítems de la encuesta en los que se observaron estas diferencias.

Los niños de estratos 1 y 2 , comparados con los de estratos 3 y 4 , mostraron consistentemente mayor convencimiento de que los niños de hoy 
son veloces para aprender, logran buenos niveles de concentración y son hábiles para la resolución de problemas de la vida diaria. Creen también más firmemente en la buena salud física de los niños, en su disciplina y en su capacidad para hacer amigos fácilmente, controlar sus emociones y comprender adecuadamente el punto de vista de otros. Por último, se inclinan más a creer que los niños cumplen estrictamente con sus deberes, tratan respetuosamente a los adultos, entienden adecuadamente los valores de convivencia y llegan a estar pronto preparados para asumir las responsabilidades de la vida adulta. Los niños de estratos 3 y 4 se mostraron particularmente escépticos frente al control de emociones, el cumplimiento estricto de deberes y la disciplina de los niños de hoy (Tabla 8).

Tabla 8. Significados en torno a la infancia en los que se diferenciaron los niños de estratos 1 y 2 de los niños de estratos 3 y 4.

\begin{tabular}{|c|c|c|c|c|c|c|}
\hline Ítem encuesta & $\begin{array}{l}\text { Opciones de } \\
\text { respuesta }\end{array}$ & $\begin{array}{c}\text { Niños } \\
\text { E.S. } 1-2 \%\end{array}$ & $\begin{array}{l}\text { Niños } \\
\text { E.S. } 3-4 \%\end{array}$ & $\begin{array}{c}\text { Niños } \\
\text { Total \% }\end{array}$ & $\begin{array}{c}\text { Puntaje } \\
\text { Chi - Cuadrado }\end{array}$ & $\begin{array}{c}\text { Nivel de } \\
\text { significancia }\end{array}$ \\
\hline Velocidad para aprender & $\begin{array}{c}\text { No } \\
\text { No sé } \\
\text { Sí }\end{array}$ & $\begin{array}{c}8.6 \\
11.4 \\
80\end{array}$ & $\begin{array}{l}15.8 \\
39.5 \\
44.7\end{array}$ & $\begin{array}{c}12.3 \\
26 \\
61.6\end{array}$ & 9,951 & .007 \\
\hline Gozar de salud física & $\begin{array}{l}\text { No } \\
\text { No sé } \\
\text { Sí }\end{array}$ & $\begin{array}{c}14.3 \\
5.7 \\
80\end{array}$ & $\begin{array}{l}39.5 \\
21.1 \\
39.5\end{array}$ & $\begin{array}{l}27.4 \\
13.7 \\
57.9\end{array}$ & 12,428 & .002 \\
\hline Hacer amigos fácilmente & $\begin{array}{l}\text { No } \\
\text { No sé } \\
\text { Sí }\end{array}$ & $\begin{array}{c}14.3 \\
0 \\
85.7\end{array}$ & $\begin{array}{l}18.9 \\
18.9 \\
62.2\end{array}$ & $\begin{array}{c}16.7 \\
9.7 \\
73.6\end{array}$ & 8,209 & 0.17 \\
\hline Control de emociones & $\begin{array}{l}\text { No } \\
\text { No sé } \\
\text { Sí }\end{array}$ & $\begin{array}{l}31.4 \\
11.4 \\
57.1\end{array}$ & $\begin{array}{l}42.1 \\
31.6 \\
26.3\end{array}$ & $\begin{array}{c}37 \\
21.9 \\
41.1\end{array}$ & 8,150 & .017 \\
\hline $\begin{array}{l}\text { Cumplimiento estricto de } \\
\text { deberes }\end{array}$ & $\begin{array}{l}\text { No } \\
\text { No sé } \\
\text { Sí }\end{array}$ & $\begin{array}{l}22.9 \\
25.7 \\
51.4\end{array}$ & $\begin{array}{l}39.5 \\
36.8 \\
23.7\end{array}$ & $\begin{array}{c}31.5 \\
31.5 \\
37\end{array}$ & 6,104 & .047 \\
\hline Saber lo que se quiere & $\begin{array}{l}\text { No } \\
\text { No sé } \\
\text { Sí }\end{array}$ & $\begin{array}{c}14.3 \\
2.9 \\
82.9\end{array}$ & $\begin{array}{l}15.8 \\
23.7 \\
60.5\end{array}$ & $\begin{array}{l}15.1 \\
13.7 \\
71.2\end{array}$ & 7,072 & .029 \\
\hline Concentración & $\begin{array}{l}\text { No } \\
\text { No sé } \\
\text { Sí }\end{array}$ & $\begin{array}{c}25.7 \\
2.9 \\
71.4\end{array}$ & $\begin{array}{l}23.7 \\
31.6 \\
44.7\end{array}$ & $\begin{array}{l}24.7 \\
17.8 \\
57.5\end{array}$ & 10,726 & .005 \\
\hline $\begin{array}{l}\text { Asunción de } \\
\text { responsabilidades }\end{array}$ & $\begin{array}{l}\text { No } \\
\text { No sé } \\
\text { Sí }\end{array}$ & $\begin{array}{c}14.7 \\
8.8 \\
76.5\end{array}$ & $\begin{array}{l}28.9 \\
23.7 \\
47.4\end{array}$ & $\begin{array}{l}22.2 \\
16.7 \\
61.1\end{array}$ & 6,502 & .039 \\
\hline $\begin{array}{l}\text { Comprensión de punto de } \\
\text { vista de otros }\end{array}$ & $\begin{array}{l}\text { No } \\
\text { No sé } \\
\text { Sí }\end{array}$ & $\begin{array}{l}31.4 \\
2.9 \\
65.7\end{array}$ & $\begin{array}{l}28.9 \\
28.9 \\
42.1\end{array}$ & $\begin{array}{l}30.1 \\
16.4 \\
53.4\end{array}$ & 9,482 & .009 \\
\hline Respeto hacia adultos & $\begin{array}{l}\text { No } \\
\text { No sé } \\
\text { Sí }\end{array}$ & $\begin{array}{c}20 \\
5.7 \\
74.3\end{array}$ & $\begin{array}{l}28.9 \\
26.3 \\
44.7\end{array}$ & $\begin{array}{l}24.7 \\
16.4 \\
58.9\end{array}$ & 7,996 & .018 \\
\hline $\begin{array}{l}\text { Habilidad para resolver } \\
\text { problemas de la vida } \\
\text { diaria }\end{array}$ & $\begin{array}{l}\text { No } \\
\text { No sé } \\
\text { Sí }\end{array}$ & $\begin{array}{l}11.4 \\
8.6 \\
80\end{array}$ & $\begin{array}{l}23.7 \\
23.7 \\
52.6\end{array}$ & $\begin{array}{l}17.8 \\
16.4 \\
65.8\end{array}$ & 6,143 & .046 \\
\hline Disciplina & $\begin{array}{l}\text { No } \\
\text { No sé } \\
\text { Sí }\end{array}$ & $\begin{array}{c}38.2 \\
5.9 \\
55.9\end{array}$ & $\begin{array}{l}44.7 \\
39.5 \\
15.8\end{array}$ & $\begin{array}{l}41.7 \\
23.6 \\
34.7\end{array}$ & 17,065 & .000 \\
\hline $\begin{array}{l}\text { Entendimiento valores de } \\
\text { convivencia }\end{array}$ & $\begin{array}{l}\text { No } \\
\text { No sé } \\
\text { Sí }\end{array}$ & $\begin{array}{c}14.3 \\
5.7 \\
80\end{array}$ & $\begin{array}{l}18.4 \\
28.9 \\
52.6\end{array}$ & $\begin{array}{l}16.4 \\
17.8 \\
65.8\end{array}$ & 7,087 & .020 \\
\hline
\end{tabular}


También en los significados en torno a la familia hubo algunas diferencias representativas entre los niños de estratos 1 y 2 y los niños de estratos 3 y 4. Cabe aclarar, no obstante, que las respuestas van en la misma dirección. Es decir, los niños en general creen que los padres los castigan poco, que respetan sus derechos y les imponen prohibiciones, pero el consenso frente a esto es mucho mayor entre los niños de estratos 1 y 2 (Tabla 9).

Tabla 9. Significados en torno a la familia en los que se diferenciaron los niños de estratos 1 y 2 de los niños de estratos 3 y 4.

\begin{tabular}{|c|c|c|c|c|c|c|}
\hline Ítems encuesta & $\begin{array}{l}\text { Opciones de } \\
\text { respuesta }\end{array}$ & $\begin{array}{c}\text { Niños } \\
\text { E.S. 1-2 } \\
\%\end{array}$ & $\begin{array}{c}\text { Niños } \\
\text { E.S. 3-4 } \\
\%\end{array}$ & $\begin{array}{c}\text { Niños } \\
\text { Total } \\
\% \\
\end{array}$ & $\begin{array}{c}\text { Puntaje } \\
\text { Chi - } \\
\text { Cuadrado }\end{array}$ & $\begin{array}{c}\text { Nivel de } \\
\text { significancia }\end{array}$ \\
\hline Poco castigo a los hijos & $\begin{array}{c}\text { No } \\
\text { No sé } \\
\text { Sí }\end{array}$ & $\begin{array}{c}17.1 \\
5.7 \\
77.1\end{array}$ & $\begin{array}{l}23.7 \\
28.9 \\
47.4\end{array}$ & $\begin{array}{l}20.5 \\
17.8 \\
61.6\end{array}$ & 8,522 & .014 \\
\hline $\begin{array}{l}\text { Respeto a los derechos de } \\
\text { los hijos }\end{array}$ & $\begin{array}{l}\text { No } \\
\text { No sé } \\
\text { Sí }\end{array}$ & $\begin{array}{c}5.7 \\
0 \\
94.3\end{array}$ & $\begin{array}{c}0 \\
18.4 \\
81.6\end{array}$ & $\begin{array}{c}2.7 \\
9.6 \\
87.7\end{array}$ & 8,954 & .011 \\
\hline Imposición de prohibiciones & $\begin{array}{l}\text { No } \\
\text { No sé } \\
\text { Sí }\end{array}$ & $\begin{array}{c}17.1 \\
2.9 \\
80\end{array}$ & $\begin{array}{l}10.5 \\
26.3 \\
63.2\end{array}$ & $\begin{array}{l}13.7 \\
15.1 \\
71.2 \\
\end{array}$ & 7.961 & .019 \\
\hline
\end{tabular}

En todos los ítems relacionados con los significados acerca de la escuela y, más concretamente, acerca de las interacciones de los profesores con sus estudiantes hubo diferencias significativas entre los niños de estraro 1 y 2 y los niños de estrato 3 y 4 . En términos generales, los primeros mostraron una valoración más positiva de la interacción que establecen los profesores con sus estudiantes. En la Tabla 10 puede observarse claramente esta tendencia, aunque nuevamente hay que aclarar que en la mayoría de los ítems las respuestas de ambos grupos de niños van en la misma dirección. Es decir, tiende a predominar una valoración positiva de la interacción profesor-estudiante. Los niños de estrato 3 y 4 , sin embargo, asumen con más frecuencia una posición crítica o al menos dubitativa. Ésta se manifiesta claramente en los ítems que hacen referencia a la capacidad de los profesores para comprender los sentimientos de los estudiantes, su disposición al diálogo y su actitud al corregir, que en un buen número de casos no es percibida como justa (Tabla 10).

Tabla 10. Significados en torno a la escuela en los que se diferenciaron los niños de estratos 1 y 2 de los niños de estratos 3 y 4 .

\begin{tabular}{|c|c|c|c|c|c|c|}
\hline Ítems encuesta & $\begin{array}{l}\text { Opciones de } \\
\text { respuesta }\end{array}$ & $\begin{array}{l}\text { Niños } \\
\text { E.S. } 1-2 \%\end{array}$ & $\begin{array}{c}\text { Niños } \\
\text { E.S. } 3-4 \%\end{array}$ & $\begin{array}{l}\text { Niños } \\
\text { Total \% }\end{array}$ & $\begin{array}{c}\text { Puntaje } \\
\text { Chi - Cuadrado }\end{array}$ & $\begin{array}{c}\text { Nivel de } \\
\text { significancia }\end{array}$ \\
\hline $\begin{array}{l}\text { Claridad para orientar a sus } \\
\text { estudiantes }\end{array}$ & $\begin{array}{l}\text { No } \\
\text { No sé } \\
\text { Sí }\end{array}$ & $\begin{array}{c}2.9 \\
0 \\
97.1\end{array}$ & $\begin{array}{l}15.8 \\
31.6 \\
52.6\end{array}$ & $\begin{array}{c}9.6 \\
16.4 \\
74\end{array}$ & 19,110 & .000 \\
\hline $\begin{array}{l}\text { Compromiso para apoyar a } \\
\text { estudiantes }\end{array}$ & $\begin{array}{l}\text { No } \\
\text { No sé } \\
\text { Sí }\end{array}$ & $\begin{array}{c}5.7 \\
11.4 \\
82.9\end{array}$ & $\begin{array}{c}28.9 \\
21.1 \\
50\end{array}$ & $\begin{array}{l}17.8 \\
16.4 \\
61.8\end{array}$ & 9,540 & .008 \\
\hline $\begin{array}{l}\text { Trato afectuoso hacia el } \\
\text { estudiante }\end{array}$ & $\begin{array}{l}\text { No } \\
\text { No sé } \\
\text { Sí }\end{array}$ & $\begin{array}{l}25.7 \\
11.4 \\
62.9\end{array}$ & $\begin{array}{l}21.1 \\
39.5 \\
39.5\end{array}$ & $\begin{array}{c}23.3 \\
26 \\
50.7\end{array}$ & 7,641 & .022 \\
\hline $\begin{array}{l}\text { Comprensión de sentimientos del } \\
\text { estudiante }\end{array}$ & $\begin{array}{l}\text { No } \\
\text { No sé } \\
\text { Sí }\end{array}$ & $\begin{array}{l}26.5 \\
17.6 \\
55.9\end{array}$ & $\begin{array}{l}55.3 \\
26.3 \\
18.4\end{array}$ & $\begin{array}{l}41.7 \\
22.2 \\
36.1\end{array}$ & 11,151 & .004 \\
\hline
\end{tabular}




\begin{tabular}{|c|c|c|c|c|c|c|}
\hline Ítems encuesta & $\begin{array}{c}\text { Opciones de } \\
\text { respuesta }\end{array}$ & $\begin{array}{c}\text { Niños } \\
\text { E.S. } 1-2 \%\end{array}$ & $\begin{array}{c}\text { Niños } \\
\text { E.S. } 3-4 \%\end{array}$ & $\begin{array}{c}\text { Niños } \\
\text { Total \% }\end{array}$ & $\begin{array}{c}\text { Puntaje } \\
\text { Chi - Cuadrado }\end{array}$ & $\begin{array}{c}\text { Nivel de } \\
\text { significancia }\end{array}$ \\
\hline $\begin{array}{l}\text { Actualización en } \\
\text { conocimientos }\end{array}$ & $\begin{array}{c}\text { No } \\
\text { No sé } \\
\text { Sí }\end{array}$ & $\begin{array}{c}0 \\
8.6 \\
91.4\end{array}$ & $\begin{array}{c}31.6 \\
21 \\
47.4\end{array}$ & $\begin{array}{l}16.4 \\
15.1 \\
68.5\end{array}$ & 18,100 & .000 \\
\hline Preparación en pedagogía & $\begin{array}{l}\text { No } \\
\text { No sé } \\
\text { Sí }\end{array}$ & $\begin{array}{c}5.7 \\
5.7 \\
88.6\end{array}$ & $\begin{array}{c}2.6 \\
52.6 \\
44.7\end{array}$ & $\begin{array}{c}4.1 \\
30.1 \\
65.8\end{array}$ & 19,053 & .000 \\
\hline $\begin{array}{l}\text { Respeto a la personalidad del } \\
\text { estudiante }\end{array}$ & $\begin{array}{l}\text { No } \\
\text { No sé } \\
\text { Sí }\end{array}$ & $\begin{array}{c}5.9 \\
2.9 \\
91.2\end{array}$ & $\begin{array}{l}28.9 \\
10.5 \\
60.5\end{array}$ & $\begin{array}{c}18.1 \\
6.9 \\
75\end{array}$ & 9,022 & .011 \\
\hline $\begin{array}{l}\text { Reconocimiento de } \\
\text { aptitudes del estudiante }\end{array}$ & $\begin{array}{l}\text { No } \\
\text { No sé } \\
\text { Sí }\end{array}$ & $\begin{array}{c}20 \\
8.6 \\
71.4\end{array}$ & $\begin{array}{c}7.9 \\
28.9 \\
63.2\end{array}$ & $\begin{array}{l}13.7 \\
19.2 \\
67.1\end{array}$ & 6,079 & .048 \\
\hline $\begin{array}{l}\text { Actitud justa al corregir al } \\
\text { estudiante }\end{array}$ & $\begin{array}{l}\text { No } \\
\text { No sé } \\
\text { Sí }\end{array}$ & $\begin{array}{c}5.7 \\
17.1 \\
77.1\end{array}$ & $\begin{array}{c}50 \\
18.4 \\
31.6\end{array}$ & $\begin{array}{l}28.8 \\
17.8 \\
53.4\end{array}$ & 19,518 & .000 \\
\hline Disposición al diálogo & $\begin{array}{l}\text { No } \\
\text { No sé } \\
\text { Sí }\end{array}$ & $\begin{array}{c}11.4 \\
20 \\
68.6\end{array}$ & $\begin{array}{l}42.1 \\
23.7 \\
34.2\end{array}$ & $\begin{array}{l}27.4 \\
21.9 \\
50.7\end{array}$ & 10,615 & .005 \\
\hline $\begin{array}{l}\text { Respeto de los derechos del } \\
\text { estudiante }\end{array}$ & $\begin{array}{l}\text { No } \\
\text { No sé } \\
\text { Sí }\end{array}$ & $\begin{array}{c}2.9 \\
5.7 \\
91.4\end{array}$ & $\begin{array}{c}7.9 \\
34.2 \\
57.9\end{array}$ & $\begin{array}{c}5.5 \\
20.5 \\
74\end{array}$ & 10,813 & .004 \\
\hline $\begin{array}{l}\text { Fomento de la } \\
\text { cooperación en el aula }\end{array}$ & $\begin{array}{l}\text { No } \\
\text { No sé } \\
\text { Sí }\end{array}$ & $\begin{array}{c}5.7 \\
2.9 \\
91.4\end{array}$ & $\begin{array}{l}18.4 \\
42.1 \\
39.5\end{array}$ & $\begin{array}{l}12.3 \\
23.3 \\
64.4\end{array}$ & 22,076 & .000 \\
\hline $\begin{array}{l}\text { Ayuda al estudiante con } \\
\text { dificultades }\end{array}$ & $\begin{array}{l}\text { No } \\
\text { No sé } \\
\text { Sí }\end{array}$ & $\begin{array}{c}5.7 \\
11.4 \\
82.9\end{array}$ & $\begin{array}{l}15.8 \\
31.6 \\
52.6\end{array}$ & $\begin{array}{c}11 \\
21.9 \\
67.1\end{array}$ & 7,543 & .023 \\
\hline Trabajo en equipo con los padres & $\begin{array}{l}\text { No } \\
\text { No sé } \\
\text { Sí }\end{array}$ & $\begin{array}{c}2.9 \\
11.4 \\
85.7\end{array}$ & $\begin{array}{l}31.6 \\
23.7 \\
44.7\end{array}$ & $\begin{array}{l}17.8 \\
17.8 \\
64.4\end{array}$ & 14,728 & .001 \\
\hline
\end{tabular}

Se observaron algunas diferencias significativas entre los padres de estratos 1 y 2 y los padres de estratos 3 y 4 en cuanto a los significados expresados en torno a la infancia. Ambos grupos de padres dudan que los niños de hoy sean más respetuosos que los de antes en su trato con los adultos. Esta posición está más fuertemente afianzada en los padres de estrato 3 y 4 . Estos últimos también se muestran claramente escépticos frente a afirmaciones como que los niños de hoy sean más disciplinados o que gocen de vínculos afectivos más fuertes que antes (Tabla 11).

Tabla 11. Significados en torno a la infancia en los que se diferenciaron los padres de estratos 1 y 2 de los padres de estratos 3 y 4.

\begin{tabular}{|c|c|c|c|c|c|c|}
\hline Ítem Encuesta & $\begin{array}{c}\text { Opciones de } \\
\text { respuesta }\end{array}$ & $\begin{array}{c}\text { Niños } \\
\text { E.S. } 1-2 \% \\
\end{array}$ & $\begin{array}{l}\quad \text { Niños } \\
\text { E.S. } 3-4 \% \\
\end{array}$ & $\begin{array}{c}\text { Niños } \\
\text { Total \% } \\
\end{array}$ & $\begin{array}{c}\text { Puntaje } \\
\text { Chi - Cuadrado }\end{array}$ & $\begin{array}{c}\text { Nivel de } \\
\text { significancia }\end{array}$ \\
\hline $\begin{array}{l}\text { Vínculos afectivos } \\
\text { más fuertes }\end{array}$ & $\begin{array}{c}\text { T.D. } \\
\text { D. } \\
\text { A. } \\
\text { T.A. }\end{array}$ & $\begin{array}{c}13.3 \\
6.7 \\
66.7 \\
13.3\end{array}$ & $\begin{array}{c}8.8 \\
50 \\
32.4 \\
8.8\end{array}$ & $\begin{array}{l}10.2 \\
36.7 \\
46.9 \\
10.2\end{array}$ & 8,595 & .035 \\
\hline $\begin{array}{l}\text { Mayor respeto } \\
\text { hacia los adultos }\end{array}$ & $\begin{array}{c}\text { T.D. } \\
\text { D. } \\
\text { A. } \\
\text { T.A. }\end{array}$ & $\begin{array}{c}37.5 \\
37.5 \\
6.3 \\
18.8\end{array}$ & $\begin{array}{c}14.7 \\
73.5 \\
11.8 \\
8\end{array}$ & $\begin{array}{c}22 \\
62 \\
10 \\
6\end{array}$ & 11,553 & .009 \\
\hline Más disciplinados & $\begin{array}{c}\text { T.D. } \\
\text { D. } \\
\text { A. } \\
\text { T.A. }\end{array}$ & $\begin{array}{c}23.5 \\
29.4 \\
47.1 \\
0\end{array}$ & $\begin{array}{c}5.9 \\
61.8 \\
26.5 \\
5.9\end{array}$ & $\begin{array}{c}11.8 \\
51 \\
33.3 \\
3.9\end{array}$ & 7,768 & .051 \\
\hline
\end{tabular}


En los significados expresados en torno a la familia sólo hubo una diferencia relevante entre los padres de estratos 1 y 2 y los de estratos 3 y 4. Entre estos últimos predomina claramente el pun- to de vista de que a los niños de hoy no se les imponen más prohibiciones que a los niños de antes. Los padres de estratos 1 y 2 tienden a pensar lo contrario (Tabla 12).

Tabla 12. Significados en torno a la familia en los que se diferenciaron los padres de estratos 1 y 2 de los padres de estratos 3 y 4 .

\begin{tabular}{lcccccc}
\hline \multicolumn{1}{c}{ Ítem Encuesta } & $\begin{array}{c}\text { Opciones de } \\
\text { respuesta }\end{array}$ & $\begin{array}{c}\text { Niños } \\
\text { E.S. 1-2 \% }\end{array}$ & $\begin{array}{c}\text { Niños } \\
\text { E.S. 3-4 \% }\end{array}$ & $\begin{array}{c}\text { Niños } \\
\text { Total \% }\end{array}$ & $\begin{array}{c}\text { Puntaje } \\
\text { Chi - Cuadrado }\end{array}$ & $\begin{array}{c}\text { Nivel de } \\
\text { significancia }\end{array}$ \\
\hline \multirow{3}{*}{ Mayor imposición de } & T.D. & 20 & 11.8 & 14.3 & & \\
prohibiciones & D. & 13.3 & 58.8 & 44.9 & 11,655 & .009 \\
& A. & 40 & 26.5 & 30.6 & & \\
\hline
\end{tabular}

T.D: Totalmente en desacuerdo

D: En desacuerdo A: De acuerdo T.A: Totalmente de acuerdo

No hubo diferencias significativas entre ambos grupos de padres en los juicios expresados en torno a la escuela. Ambos tendieron, en general, a valorar positivamente la interacción que establecen los profesores con sus estudiantes.

Al comparar las respuestas de los profesores frente a los ítems relacionados con las características actuales de la infancia, encontramos que hay algunas diferencias significativas entre los profeso- res de los estratos 1 y 2 y los de estratos 3 y 4 . Estos últimos tienden a dudar que los niños de hoy hagan amigos más fácilmente que los de antes. Asimismo, se inclinan a pensar que los niños hoy no llegan a saber más pronto qué es lo que quieren y no son más recursivos para la resolución de problemas de la vida diaria. Los puntos de vista de los profesores vinculados a instituciones de estratos 1 y 2 frente a estos ítems tienden, por el contrario, a ser confirmativos (Tabla 13).

Tabla 13. Significados en torno a la infancia en los que se diferenciaron los profesores que trabajan con estratos 1 y 2 de los profesores que trabajan con estratos 3 y 4.

\begin{tabular}{|c|c|c|c|c|c|c|}
\hline Ítem Encuesta & $\begin{array}{l}\text { Opciones de } \\
\text { respuesta }\end{array}$ & $\begin{array}{c}\text { Niños } \\
\text { E.S. } 1-2 \%\end{array}$ & $\begin{array}{c}\text { Niños } \\
\text { E.S. } 3-4 \%\end{array}$ & $\begin{array}{c}\text { Niños } \\
\text { Total \% }\end{array}$ & $\begin{array}{c}\text { Puntaje } \\
\text { Chi - Cuadrado }\end{array}$ & $\begin{array}{c}\text { Nivel de } \\
\text { significancia }\end{array}$ \\
\hline Hacer amigos más fácilmente & $\begin{array}{c}\text { T.D. } \\
\text { D. } \\
\text { A. } \\
\text { T.A. }\end{array}$ & $\begin{array}{c}3.8 \\
0 \\
53.8 \\
42.3\end{array}$ & $\begin{array}{c}7.7 \\
38.5 \\
30.8 \\
23.1\end{array}$ & $\begin{array}{c}5.8 \\
19.2 \\
42.3 \\
32.7\end{array}$ & 13,440 & .004 \\
\hline Saber más pronto lo que se quiere & $\begin{array}{c}\text { T.D. } \\
\text { D. } \\
\text { A. } \\
\text { T.A. }\end{array}$ & $\begin{array}{l}11.5 \\
26.9 \\
34.6 \\
26.9\end{array}$ & $\begin{array}{c}15.4 \\
65.4 \\
19.2 \\
0\end{array}$ & $\begin{array}{l}13.5 \\
46.2 \\
26.9 \\
13.5\end{array}$ & 12.452 & .006 \\
\hline $\begin{array}{l}\text { Mayor recursividad para resolver } \\
\text { problemas de la vida diaria }\end{array}$ & $\begin{array}{c}\text { T.D. } \\
\text { D. } \\
\text { A. } \\
\text { T.A. }\end{array}$ & $\begin{array}{c}11.5 \\
3.8 \\
73.1 \\
11.5\end{array}$ & $\begin{array}{c}3.8 \\
61.5 \\
26.9 \\
7.7\end{array}$ & $\begin{array}{c}7.7 \\
32.7 \\
50 \\
9.6\end{array}$ & 19,974 & .000 \\
\hline
\end{tabular}

T.D: Totalmente en desacuerdo

En lo relacionado con la familia, los profesores vinculados a instituciones de estratos 1 y 2 y los de estratos 3 y 4 se diferenciaron en sus apreciaciones sobre si los padres de hoy miman más a sus hijos y les ofrecen más reconocimiento. Mientras los profesores de los estratos 3 y 4 tienden a responder positivamente a estos cuestionamientos, los profesores de los estratos 1 y 2 se inclinan más 
hacia el punto de vista opuesto. Es decir, no creen que los padres hoy mimen más a sus hijos o les brinden más reconocimiento (Tabla 14).

Tabla 14. Significados en torno a la familia en los que se diferenciaron los profesores que trabajan con estratos 1 y 2 de los profesores que trabajan con estratos 3 y 4 .

\begin{tabular}{lcccccc}
\hline \multicolumn{1}{c}{ Ítem Encuesta } & $\begin{array}{c}\text { Opciones de } \\
\text { respuesta }\end{array}$ & $\begin{array}{c}\text { Niños } \\
\text { E.S. 1-2 \% }\end{array}$ & $\begin{array}{c}\text { Niños } \\
\text { E.S. 3-4 \% }\end{array}$ & $\begin{array}{c}\text { Niños } \\
\text { Total \% }\end{array}$ & $\begin{array}{c}\text { Puntaje } \\
\text { Chi - Cuadrado }\end{array}$ & $\begin{array}{c}\text { Nivel de } \\
\text { significancia }\end{array}$ \\
\hline \multirow{4}{*}{ Mimar más a los hijos } & T.D. & 15.4 & 0 & 7.7 & & \\
& D. & 38.5 & 15.4 & 26.9 & 9,597 & .022 \\
Brindar más reconocimiento a los & A. & 26.9 & 53.8 & 40.4 & & \\
hijos & T.A. & 19.2 & 30.8 & 25 & & \\
& T.D. & 15.4 & 0 & 7.7 & & \\
& D. & 42.3 & 23.1 & 32.7 & \multirow{2}{*}{8,097} & \\
\hline
\end{tabular}

Por último, hubo algunas diferencias significativas en la forma como los profesores de los estratos 1 y 2 y los de los estratos 3 y 4 percibieron su compromiso frente a los estudiantes y su grado de actualización en conocimientos. Las diferencias son de grado o énfasis, mas no de contenido, ya que tanto los unos como los otros están en su gran mayoría de acuerdo con que los profesores están hoy más actualizados que antes y muestran mayor compromiso con sus estudiantes (Tabla 15).

Tabla 15. Significados en torno a la escuela en los que se diferenciaron los profesores que trabajan con estratos 1 y 2 de los profesores que trabajan con estratos 3 y 4 .

\begin{tabular}{lcccccc}
\hline \multicolumn{1}{c}{ Ítem Encuesta } & $\begin{array}{c}\text { Opciones de } \\
\text { respuesta }\end{array}$ & $\begin{array}{c}\text { Niños } \\
\text { E.S. 1-2 \% }\end{array}$ & $\begin{array}{c}\text { Niños } \\
\text { E.S. 3-4 \% }\end{array}$ & $\begin{array}{c}\text { Niños } \\
\text { Total \% }\end{array}$ & $\begin{array}{c}\text { Puntaje } \\
\text { Chi - Cuadrado }\end{array}$ & $\begin{array}{c}\text { Nivel de } \\
\text { significancia }\end{array}$ \\
\hline \multirow{3}{*}{$\begin{array}{l}\text { Mayor compromiso para apoyar a } \\
\text { los estudiantes }\end{array}$} & T.D. & 0 & 0 & 0 & & \\
& D. & 4 & 7.7 & 5.9 & 9,870 & .007 \\
Más actualizados en sus conoci- & T.A. & 56 & 88.5 & 72.5 & & \\
mientos & T.D. & 0 & 3.8 & 21.6 & & \\
& D. & 3.8 & 0 & 0 & & \\
& A. & 34.6 & 73.1 & 53.8 & 8,093 & \\
\hline
\end{tabular}

T.D: Totalmente en desacuerdo

D: En desacuerdo

\section{Discusión}

Al analizar los juicios expresados acerca de los rasgos característicos de la infancia en la actualidad, podemos concluir que tanto los niños, como los padres de familia y los profesores resaltan especialmente ciertos aspectos del desarrollo cognitivo de los niños de hoy, como son la velocidad con que aprenden, el conocimiento que tienen del mundo que los rodea y la recursividad con que resuelven distintos problemas de la vida diaria. Los profesores se muestran particularmente escépticos frente a la capacidad de concentración
A: De acuerdo T.A. Totalmente de acuerdo

y la memoria de los niños. En este punto no estarían mejor los niños de ahora que los de antes.

Esto nos conduce a una serie de interrogantes importantes: ¿Hasta qué punto la escuela de hoy está logrando captar la atención y motivación de los estudiantes? ¿Está cambiando la escuela flexiblemente en función de los cambios que está experimentando la sociedad en el contexto de la globalización? ¿Se han transformado significativamente las prácticas y métodos pedagógicos? ¿Afecta el contacto intensivo de los niños con los medios de comunicación su concentración en la escuela? Dado 
que una queja frecuente de los profesores es la falta de concentración que muestran los niños en el aula de clase, puede ser pertinente profundizar la investigación en este campo, para comprender mejor qué factores están involucrados.

En lo que concierne al desarrollo emocional de los niños, los tres grupos de participantes coinciden en dudar de la capacidad actual de los niños para soportar frustraciones. También se inclinan a pensar que los niños actualmente sufren de problemas emocionales y, según los padres y profesores, más que los niños de antes. En este punto es importante destacar el notable escepticismo que exteriorizan los profesores frente a la capacidad de control emocional de los niños, sus vínculos afectivos, su felicidad y el grado de preparación con que cuentan para asumir pronto responsabilidades en la sociedad.

En efecto, mientras los niños tienden a emitir juicios positivos frente a lo anterior, los padres se ubican entre la duda y la complacencia, y sólo los maestros demuestran una notable posición crítica. Todo esto parece estar indicando que los profesores perciben déficit en el desarrollo emocional de los niños, que son percibidos en menor escala por los padres de familia y que casi no son percibidos por los niños. Cabe puntualizar aquí que en nuestro país los horarios escolares tienden a extenderse cada vez más y los profesores probablemente se ven obligados a sustituir parcialmente a los padres en lo que se refiere a la educación emocional de los niños.

Por otro lado, está el hecho bastante documentado de la vinculación de ambos padres al mundo del trabajo, la extensión e irregularidad mayor de las jornadas laborales actuales y el menor tiempo real compartido entre los miembros de la familia. Todos estos cambios podrían verse reflejados en el desarrollo emocional de los niños y se harían especialmente patentes en la escuela, dado que ésta es actualmente el escenario en el que los niños pasan la mayor parte del tiempo, en los días hábiles de la semana.

Es importante destacar también la notoria coincidencia que se observó entre los tres grupos de participantes frente a la baja tolerancia a la frustración de los niños de hoy. Esto podría ser un indicador de un proceso evolutivo a través del cual el control de impulsos y de emociones por parte de los niños se estaría debilitando en un contexto en el que los medios de comunicación hacen un excesivo énfasis en la gratificación inmediata de necesidades y deseos. Algunos autores han expresado ya su preocupación, por la forma como hoy se diseñan estrategias comerciales para incrementar el consumo en los niños, a la vez que se les tiende a utilizar crecientemente como protagonistas de pautas publicitarias.

En lo relacionado con la integración armónica de los niños en contextos referenciales, tales como la familia, la escuela o el grupo de amigos, se observa que los tres grupos de participantes concuerdan en afirmar que los niños de hoy hacen más fácilmente amistades y son más autónomos frente a sus padres, sin que por esto dejen de necesitar la guía que éstos pueden proporcionarles.

Resulta evidente en este sentido que los niños disponen hoy de más medios para establecer y mantener contacto con múltiples personas, a la vez que tienen un acceso más fácil a fuentes de información que les permiten gozar de creciente independencia frente a sus padres. Internet, la telefonía celular y la misma televisión, entre otros medios, facilitan el rápido acceso a una gran diversidad de personas e informaciones, pero por lo mismo pueden constituirse también en fuente de riesgos para el desarrollo de los niños, dado que con frecuencia no están preparados para comprender adecuadamente los mensajes que reciben $\mathrm{y}$, por tanto, pueden no tomar oportunamente distancia de personas o informaciones que amenazan con causarles daño. Llama la atención en este punto, que tanto los niños como los padres de familia y los profesores, reivindiquen el papel fundamental que desempeñan los padres como guías y protectores de sus hijos.

En los padres y los profesores se observa que manifiestan duda frente a ciertos aspectos tradicionales en la socialización de los niños que hoy no estarían marchando mejor que antes. Ejemplos de ello son la práctica de buenos modales, el res- 
peto hacia las personas adultas, la disciplina y el cumplimiento estricto de los deberes. Cabe preguntarse si los estilos y objetivos de crianza han cambiado hoy significativamente en el sentido de un descenso en los niveles de exigencia en cuanto a la obediencia y las responsabilidades que los niños tienen que asumir en el hogar.

Algunos estudios sugieren que los padres estarían experimentando hoy una mayor inseguridad frente al ejercicio de su rol como educadores, debido al ritmo acelerado de cambio y a un cierto relativismo que se ha extendido en lo referente a creencias y valores. Esta inseguridad se reflejaría en una mayor inconsistencia o permisividad frente a las actuaciones de sus hijos. Por otro lado, sin embargo, es importante reconocer que los niños hoy estarían también más "empoderados", en el sentido de que, como lo manifiestan los tres grupos de participantes en la encuesta, conocen mejor sus derechos y pueden defender mejor sus puntos de vista frente a las personas adultas y esto puede ser interpretado por éstas como falta de respeto, irreverencia o renuencia a cumplir con sus deberes.

En cuanto a la capacidad de los niños para comprender el punto de vista de los demás y entender los valores de convivencia, son nuevamente los maestros quiénes más frecuentemente se muestran escépticos. Esto parece estar relacionado con el análisis que realizaremos a continuación sobre la interacción que se establece actualmente entre los padres de familia y sus hijos, visto desde la perspectiva de los profesores, cuya postura predominantemente crítica llama la atención.

En efecto, según el punto de vista de la mayoría de ellos, los padres de hoy, comparados con los padres de antes, no tienen mayor claridad sobre cómo educar a sus hijos, no comparten más tiempo con ellos, no les brindan mejor apoyo escolar, no dialogan más con ellos ni comprenden mejor sus sentimientos y tampoco los acompañan más en los momentos importantes de su vida.

Esto podría interpretarse de dos maneras, o que no ha habido evolución en la forma como los padres desempeñan estas funciones importantes para el desarrollo de los niños, o que, incluso, ha empeorado la forma como cumplen con estas funciones. Cabe anotar que los padres están de acuerdo con algunas de estas posturas críticas, especialmente las que se refieren al tiempo compartido con los hijos y al apoyo escolar. Pero, en general, su visión frente al desempeño actual del rol parental, tiende a ser positiva, aceptando que los padres de familia hoy muestran avances frente a los padres de familia de antes. La visión de los niños tiende a ser más claramente positiva, aún estando divididos sólo respecto a si los padres comparten bastante tiempo con sus hijos o no, y si logran realmente adivinar sus pensamientos.

Lo anterior nos lleva a concluir que son probablemente los profesores, como representantes de la institución escolar, quienes están experimentando más dramáticamente las consecuencias de los cambios que están teniendo lugar en la infancia y la familia en conexión con los procesos de globalización. Empecemos por llamar la atención sobre el hecho de que la escuela, y más concretamente la interacción que se da actualmente entre los profesores y los estudiantes, obtuvo en este estudio una valoración bastante positiva, tanto de los niños como de los padres y profesores. Esto podría estar indicando que hay grandes expectativas frente a la institución escuela, lo que conlleva el riesgo de que los profesores comiencen a sentirse sobrecargados de responsabilidades frente a los niños y muy limitados, por otro lado, para lograr una cooperación eficaz con los padres de familia.

Frecuentemente, se subraya el hecho de que la escuela está asumiendo en forma creciente roles que antes estaban casi exclusivamente reservados a la familia. En efecto, cada vez se le solicita más no ser sólo un lugar donde los niños adquieren muy variados conocimientos, sino también ser un nicho en el que se desarrollan lazos afectivos fuertes, se aprenden valores de convivencia y en general, se forma a seres humanos integrales. Son por eso grandes los retos que afronta la institución escolar en la actualidad. En un mundo altamente competitivo y sumido en la constante incertidumbre del cambio, se ve obligada a reacomodarse en forma rápida y continua para seguir siendo competente en el cumplimiento de su mi- 
sión educativa. Y es probable que los docentes sientan especialmente el peso de esta presión. De ahí su postura significativamente más crítica y escéptica.

Cuando se hace un análisis comparativo de los significados expresados por los niños, padres de familia y profesores vinculados a instituciones escolares de estratos 1 y 2 con los vinculados a instituciones escolares de estratos 3 y 4 encontramos algunos resultados interesantes.

Lo primero que salta a la vista es que las diferencias más significativas se dan entre los niños. Los niños de estratos 1 y 2 tienden en general a tener una visión más positiva acerca de la infancia actual. Esto resulta particularmente interesante si se tiene en cuenta que son precisamente estos niños los que deben afrontar mayores privaciones y obstáculos para su desarrollo. Cabría preguntarse si esto tiene que ver con el contexto escolar en que ellos se desenvuelven. Podría argumentarse, por ejemplo, que los niños de estratos socioeconómicos 3 y 4 gozan de ambientes escolares más ricos en recursos y oportunidades y que la educación que allí se imparte tiende a ser más democrática, más extensa a nivel de contenidos y más centrada en fortalecer el juicio crítico y la autonomía intelectual de los estudiantes. Otra explicación posible podría ser que a través de los significados que construyen sobre sí mismos, los niños tratan de fortalecerse frente a la adversidad.

Llama la atención en este punto, que los niños de estratos socioeconómicos 1 y 2 muestren además un mayor consenso al juzgar que sus padres los castigan poco y respetan sus derechos. Los estudios sobre prácticas de crianza sugieren que precisamente en los sectores de bajos ingresos son más usuales el castigo (sobre todo el castigo físico) y las violaciones de los derechos de los niños. Además, los padres tienden a adoptar un estilo de crianza más autoritario. Las respuestas antes mencionadas de los niños de estratos 1 y 2 hacen pensar que, o tienen una visión menos crítica acerca de las condiciones en que son educados, o las prácticas de crianza se han ido democratizando y los niños perciben esta tendencia.
También en los significados expresados acerca de la escuela los niños de estratos 1 y 2 se mostraron especialmente menos críticos en relación con sus profesores que los niños de estratos socioeconómicos 3 y 4. Estos últimos, por ejemplo, tienden a dudar de que los profesores comprendan sus sentimientos, que tengan un trato afectuoso con ellos, que estén dispuestos al diálogo y que sean justos al corregirlos. Nuevamente llama la atención el amplio consenso que logran los niños de estratos socioeconómicos 1 y 2 al valorar positivamente la interacción con los profesores en casi cada ítem relacionado con esto.

Al realizar el mismo análisis con padres y profesores de estratos socioeconómicos diferentes (estrato 1 y 2 comparado con estrato 3 y 4 ) se encontraron pocas diferencias significativas que, no obstante, son interesantes. Los padres de estratos 1 y 2 , en contraposición con los de estratos 3 y 4 creen que los niños de hoy gozan de vínculos afectivos más fuertes, pero al mismo tiempo piensan que hoy se les imponen más prohibiciones a los niños en la familia. Cabe preguntarse si estos juicios están indicando una creciente sensibilización en las familias de ingresos bajos frente a las necesidades de los niños y una postura crítica frente al autoritarismo que tradicionalmente se daba en la educación. Ambos grupos de padres tienden a dudar de la disciplina y el respeto hacia los adultos de los niños de hoy. Sin embargo, los grados y énfasis con que se expresan estas tendencias son diferentes. De ahí que también aparezcan diferencias significativas frente a estos conceptos.

Por último, cabe resaltar que los profesores que trabajan en instituciones escolares de estratos socioeconómicos 3 y 4 a diferencia de los que lo hacen en instituciones de estratos 1 y 2 se inclinan a considerar que los padres de hoy miman más a los hijos y les brindan más reconocimiento. Esto parece confirmar los puntos de vista de los padres que se describieron en el párrafo anterior.

Falta realizar más investigación en este sentido con el fin de lograr una mejor comprensión de los cambios que están teniendo lugar en los contextos educativos y la forma cómo estos cambios se 
relacionan con los significados que construyen los niños acerca de la infancia, la familia y la escuela. Una parte de este proyecto de investigación que se publicará en artículos independientes a éste, se dirigirá al análisis de las expresiones espontáneas de los niños, padres de familia y profesores cuando en un grupo focal discuten abiertamente sobre estos temas.

\section{Referencias}

Arriagada, I. \& Aranda, V. (compiladoras) (2004). Cambio de las familias en el marco de las transformaciones globales: necesidad de políticas públicas eficaces. Santiago: CEPAL, División de Desarrollo Social.

Antúnez, J. (2001). Globalización, economía y familia. Revista Humanitas, 22.

Beck, U. (2002). Democratización de la familia. En: Beck, U. (comp.). Hijos de la libertad (pp. 172193). México: Fondo de Cultura Económica.

Beck, U. (2008). Generación global. Madrid: Paidós.

Bernal, T. (2009). La escuela: el lugar de los niños y de las niñas. Bogotá, Universidad Santo Tomás, en trámite de publicación.

Cohen, S. \& Wills, T. (1985). Stress, social support and the buffering hypothesis. Psychological Bulletin, 98, 310-357.

Coulton, C., Korbin, J., Su, M. \& Chow, J. (1995). Community level factors and child maltreatment rates. Child Development, 66, $1262-1276$.

De Zubiría, J. (2003). De la escuela nueva al constructivismo. Bogotá: Magisterio.

Dieterich, H. (1996). Globalización, educación y democracia en América Latina. En: Chomsky, N. \& Dieterich, H. (Eds). La sociedad global: educación, mercado y democracia. Santiago: Lom Ediciones.
Flecha, R. \& Tortajada, I. (1999). Retos y salidas educativas en la entrada del siglo XXI: los retos del futuro inmediato. Barcelona: Biblioteca de Aula.

Florenzano, R. (1998). Familia y salud de los jóvenes. Familia y crisis conyugal. Santiago: PUC de Chile.

Hayes, A. (2008). Are family changes, social trends and unanticipated policy consequences making children's lives more challenging? Family Matters, 78. Australian Institute of family studies. Recuperado el 30 de junio de http://www.aifs.gov.au/institute/pubs/ fm2008/fm78/ah.pdf.

Huntington, S. (1993). The clash of civilizations. University of Leeds, Institut of communications studies. Recuperado el 30 de junio de http://ics.leeds.ac.uk/papers/vf01. cfm?folder=49\&outfit=pmt.

Jaramillo, J. (1998). Políticas y concepciones acerca del trabajo infantil. En: Memorias del Seminario Latinoamericano: Un nuevo siglo sin trabajo infantil. Bogotá, publicación del programa IPEC-OIT y el Instituto Colombiano de Bienestar Familiar (ICBF).

Kershner, J. \& Cohen, N. (1992). Maternal depressive symptoms and child functioning. Journal of Applied Developmental Psychology, 13, 5163.

Klippert, H. (2004). Trabajo y aprendizaje asumidos con responsabilidad propia. Lima: Edición y traducción del Colegio Alemán Max-Uhle.

Petzold, M. (2001). Verändern die neuen Medien unsere Kinder und Jugendlichen? Recuperado el 30 de junio de http://www. familienhandbuch.de/cmain/f_Fachbeitrag/a Jugendforschung/s_1115.html.

Rice, P. (1997). Desarrollo humano: un estudio del ciclo vital. México: Prentice Hall. 
Srinivas, R. (2007). Globalización y sostenibilidad ambiental. Documento de trabajo para el diplomado: Efectos de la Globalización. University of St. Thomas Houston.

Torrado, M.C. (2007). La convención de derechos de los niños como marco para pensar la política social. En: Durán, E. \& Torrado, M.C. (comp.). Derechos de los niños y las niñas: debates, realidades y perspectivas (pp. 6575) Bogotá: Universidad Nacional de Colombia, Centro de Estudios Sociales.

Torres, A. \& Morrow, R. (2005). Estado, globalización y política educacional. En: Morrow, R., Apple, M. \& Popkewitz, T. (comp.). Globalización y Educación: manual crítico (pp. 3158). Madrid: Popular.
UNICEF (2006). Globalización e infancia. Recuperado el 30 de junio de www.unicef.org/spanish/ media/files/Globalizacion_e_infancia.pdf.

Walsh, J. (1993). Niños y jóvenes de hoy: entre la competencia y el consumismo. México: Gedisa.

Winterhoff, M. (2008). Warum unsere Kinder Tyrannen werden oder: Die Abschaffung der Kindheit. Muenchen: Guetersloher Verlag.

Ziegler, J. (2005). Das Imperium der Schande: der Kampf gegen Armut und Unterdruckung. Muenchen: Pantheon. 